\title{
IMPACTS OF NATURAL ORGANIC MATTER ON PERCHLORATE REMOVAL BY AN ADVANCED REDUCTION PROCESS
}

\author{
A Thesis \\ by \\ YUHANG DUAN \\ Submitted to the Office of Graduate Studies of \\ Texas A\&M University \\ in partial fulfillment of the requirements for the degree of \\ MASTER OF SCIENCE
}

August 2012

Major Subject: Civil Engineering 
Impacts of Natural Organic Matter on Perchlorate Removal by an Advanced Reduction

Process

Copyright 2012 Yuhang Duan 


\title{
IMPACTS OF NATURAL ORGANIC MATTER ON PERCHLORATE REMOVAL BY AN ADVANCED REDUCTION PROCESS
}

\author{
A Thesis \\ by \\ YUHANG DUAN \\ Submitted to the Office of Graduate Studies of \\ Texas A\&M University \\ in partial fulfillment of the requirements for the degree of \\ MASTER OF SCIENCE
}

Approved by:

Chair of Committee, Bill Batchelor

Committee Members, Bryan Boulanger

Yongheng Huang

Head of Department, John Niedzwecki

August 2012

Major Subject: Civil Engineering 


\author{
ABSTRACT \\ Impacts of Natural Organic Matter on Perchlorate Removal by an Advanced Reduction \\ Process. (August 2012) \\ Yuhang Duan, B.S., Hebei Agricultural University in China \\ Chair of Advisory Committee: Dr. Bill Batchelor
}

Perchlorate is one of the major emerging contaminants of concern and has been found in soil and water systems throughout the United States. Human exposures to perchlorate could occur by ingestion of contaminated water and food as well as by skin contact. Studies show that perchlorate blocks the sodium iodide symporter (NIS) protein in human body, which results in several diseases. It has been demonstrated that perchlorate can be removed by Advanced Reduction Processes (ARPs) that combine chemical reductants (e.g. sulfite) with activating methods (e.g. UV light) in order to produce highly reactive reducing free radicals that are capable of rapid and effective perchlorate reduction.

However, other compounds in a real system might inhibit or promote this reduction process. Natural organic matter (NOM) widely exists in the environment and it can absorb UV light, so it has the potential to influence the process of perchlorate reduction by ARPs that use UV light as the activating method. Therefore, batch experiments were conducted to obtain data on the impacts of natural organic matter and 
light intensity on destruction of perchlorate by the ARPs that use sulfite activated by ultraviolet light produced by low-pressure mercury lamps or $\mathrm{KrCl}$ excimer lamps.

The results indicate that NOM strongly inhibits perchlorate removal by either the sulfite/UV-KrCl or the sulfite/UV-L ARP, because NOM competes with sulfite for UV light and can possibly scavenge sulfite radicals. Even though the absorbance of sulfite is much higher at UV wavelength of $222 \mathrm{~nm}$ than that at $254 \mathrm{~nm}$, the results indicate that a higher portion of perchlorate was removed with the UV-L lamp than with the UV-KrCl lamp. The results of this study will help to develop the proper way to apply the ARPs in a real wastewater treatment plant. 


\section{DEDICATION}

This thesis is dedicated to my parents who offered me unconditional love and support throughout my studies, and all my friends who always provided their encouragement and support to me. 


\section{ACKNOWLEDGEMENTS}

I owe my deepest gratitude to my committee members, my friends, and my family, without whom this thesis would not have been possible.

I would like to thank my committee chair, Dr. Bill Batchelor, who provided me an opportunity to be a research group member and let me involved into a great research project, patiently corrected my writing, and financially supported my research which is very important to a international student. I would also like to thank my committee members, Dr. Bryan Boulanger, Dr. Yongheng Huang, for their guidance and support throughout the course of this research. They all provided their positive guidance and intellectual background to help push this project to complete on time.

I would like to show my special gratitude to three research group members, $\mathrm{Mr}$. Bhanu Prakash, Mr. Xu Liu and Mr. Venkata Sai Vamsi Botlaguduru, who taught me step by step to operate the relative instruments at the beginning of my studies and shared their ideas and opinions throughout the course of this research. Thanks also go to Dr. Sanjay Tewari-another research group member, for the friendship.

I would like to thank my friends, for the exhilarating time we spent together and our great friendship, without whom I would have a boring time.

I would like to thank the department faculty and staff for making my time at Texas A\&M University a great experience.

Finally, thanks to my grandfather and my parents for their lovely concerns, encouragement, and financial support for first three semesters at Texas A\&M 
University-College Station, which was a big burden for them. Thanks also go to my younger brother and my cousins who always provide their best wishes. 


\section{NOMENCLATURE}

\begin{tabular}{|c|c|}
\hline AOP & Advanced Oxidation Process \\
\hline ARP & Advanced Reduction Process \\
\hline CCL & Contaminant Candidate List \\
\hline CSTR & Continuous-Flow Stirred Tank Reactors \\
\hline DBPs & Disinfection By-Products \\
\hline DI & Deionized \\
\hline DL & Detection Limit \\
\hline DWEL & Drinking Water Equivalent Level \\
\hline FBR & Fluidized Bed Reactor \\
\hline $\mathrm{IC}$ & Ion Chromatography \\
\hline MDL & Method Detection Limit \\
\hline MRL & Minimum Reporting Level \\
\hline NIS & Sodium Iodide Symporter \\
\hline NOM & Natural Organic Matter \\
\hline NPDWR & National Primary Drinking Water Regulation \\
\hline PQL & Practical Quantitation Limits \\
\hline PRB & Packed Bed Reactor \\
\hline RfD & Reference Dose \\
\hline SUVA & Specific UV-Absorbance \\
\hline UHP & Ultra High Purity \\
\hline
\end{tabular}


U.S. EPA United States Environmental Protection Agency

UV Ultraviolet

UV-KrCl Narrow Band $\mathrm{KrCl}$ Ultraviolet Excimer Lamp

UV-L Ultraviolet Low-Pressure Mercury Lamp 


\section{TABLE OF CONTENTS}

Page

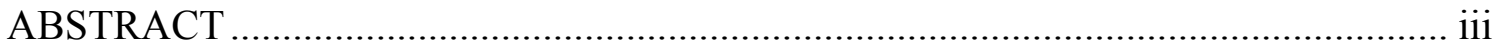

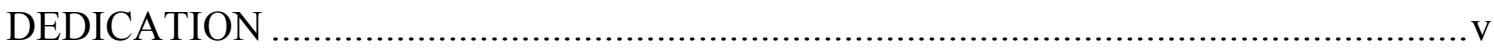

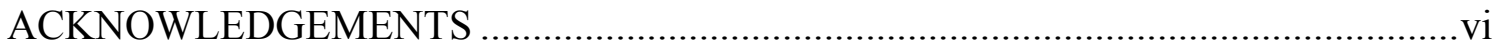

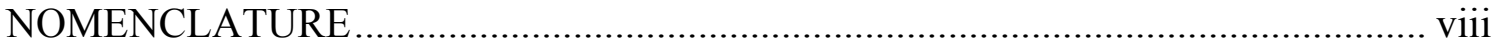

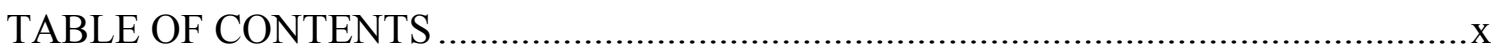

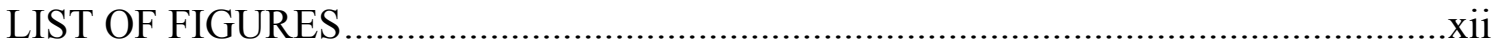

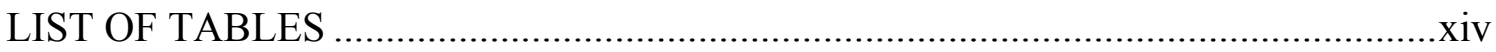

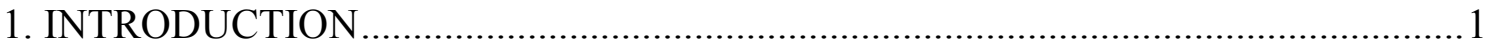

2. BACKGROUNDS AND HISTORY …...........................................................

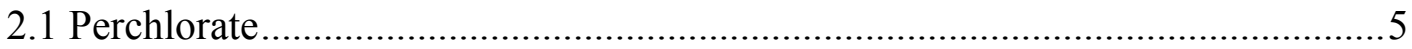

2.1.1 Physical and Chemical Properties ....................................................

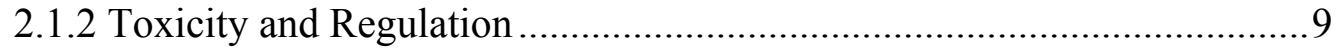

2.2 Characteristics of Natural Organic Matter ................................................. 10

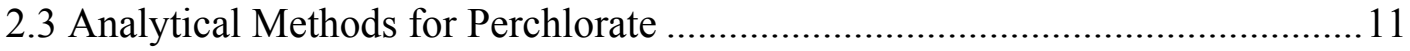

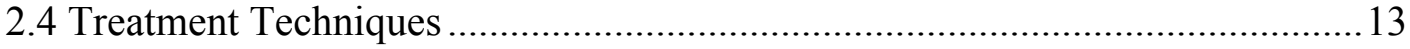

2.4.1 Current Treatment Technologies..................................................... 13

2.4.2 Advanced Reduction Processes............................................................ 16

3. EXPERIMENTAL METHODS AND MATERIALS .............................................20

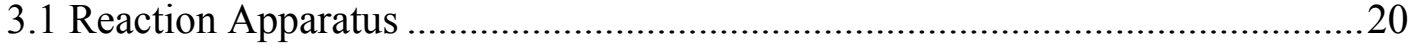

3.1.1 UV Lamps .................................................................................. 20

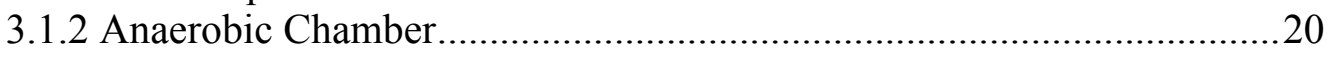

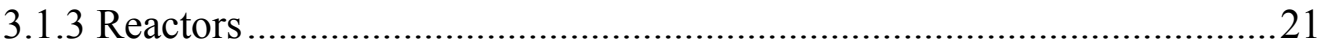

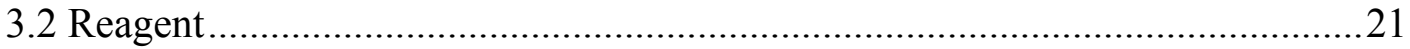

3.2.1 Deoxygenated Deionized Water.....................................................21

3.2.2 Perchlorate Standards ...................................................................... 21

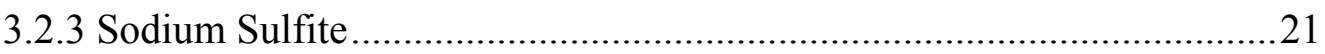

3.2.4 Potassium Hydrogen Phosphate Stock Solution ..................................22 
3.2.5 Suwannee River Natural Organic Matter ...........................................22

3.2.6 Sodium Hydroxide Stock Solution....................................................23

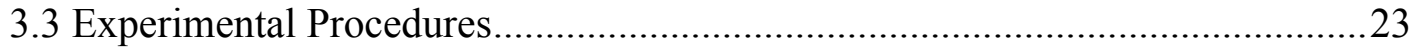

3.3.1 Constant Conditions .......................................................................23

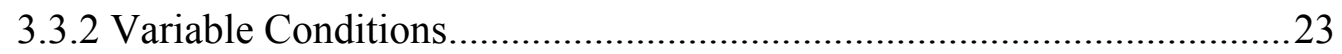

3.3.3 Kinetic Experiments .......................................................................23

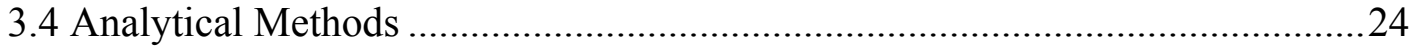

4. CHARACTERISTICS OF PERCHLORATE REDUCTION BY ARP ....................26

4.1 Perchlorate Reduction by Sulfite/UV-KrCl ARP .........................................26

4.2 Perchlorate Reduction by Sulfite/UV-L ARP ................................................. 33

4.3 Comparison of Sulfite/UV-L and Sulfite/UV-KrCl ARPs.............................. 38

5. IMPACT OF NOM ON PERCHLORATE REDUCTION BY ARP ........................41

5.1 Effects of NOM on Perchlorate Reduction by Sulfite/UV-KrCl ARP..............41

5.1.1 Effect of NOM on Perchlorate Removal.............................................4 41

5.1.2 Loss of NOM-absorbance .............................................................. 43

5.1.3 Loss of Sulfite ............................................................................. 44

5.2 Effects of NOM on Perchlorate Reduction by Sulfite/UV-L ARP ..................47

5.2.1 Effect of NOM on Perchlorate Removal ............................................4 47

5.2.2 Loss of NOM-absorbance ..............................................................49

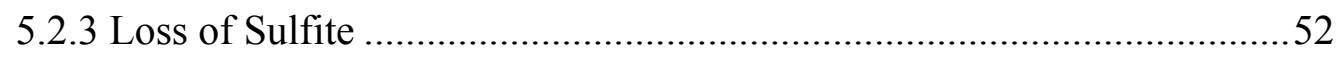

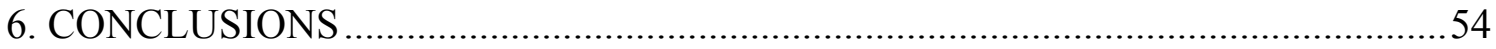

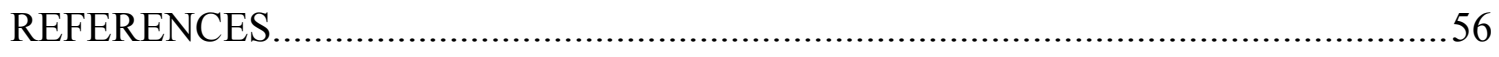

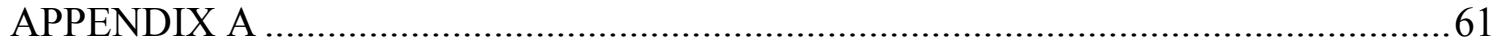

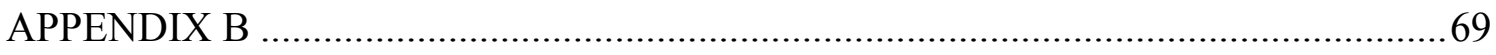

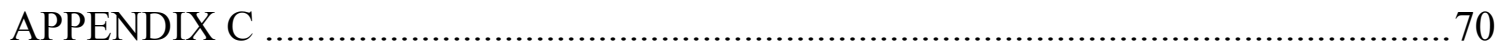

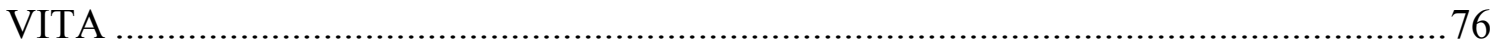




\section{LIST OF FIGURES}

Page

Figure 1 Perchlorate manufacturers and users in the United States as of April, 2003

Figure 2 Perchlorate releases in the United States as of April, 2003

Figure 3 The structure of perchlorate anion

8

Figure 4 Schematic of biological reduction of perchlorate

Figure 5 Removal of perchlorate $\left(\mathrm{ClO}_{4}^{-}\right)$and production of chloride ions $\left(\mathrm{Cl}^{-}\right)$with and without sulfite and $\mathrm{UV}-\mathrm{KrCl}$ lamp $\left([\text { perchlorate }]_{\text {initial }}=10 \mathrm{mg} / \mathrm{L} \text {, [sulfite }\right]_{\text {initial }}=11 \mathrm{mM}$; $\mathrm{UV}-\mathrm{KrCl}$ lamp intensity $=13 \mathrm{~mW} / \mathrm{cm}^{2}, \mathrm{pH}=11$ ).

Figure 6 Consumption of sulfite $\left(\mathrm{SO}_{3}{ }^{2-}\right)$ with $\mathrm{UV}-\mathrm{KrCl}$ lamp with and without perchlorate $([\text { sulfite }]=11 \mathrm{mM} \text {, [perchlorate }]_{\text {initial }}=10 \mathrm{mg} / \mathrm{L}$; $\mathrm{UV}-\mathrm{KrCl}$ lamp intensity $=13 \mathrm{~mW} / \mathrm{cm}^{2}, \mathrm{pH}=11$ )

Figure 7 Removal of perchlorate $\left(\mathrm{ClO}_{4}{ }^{-}\right)$with and without irradiation by a UV-L lamp $\left([\text { perchlorate }]_{\text {initial }}=10 \mathrm{mg} / \mathrm{L}\right.$, [sulfite $]=11 \mathrm{mM}$;

$\mathrm{UV}-\mathrm{L}$ intensity $\left.=9.5 \mathrm{~mW} / \mathrm{cm}^{2}, \mathrm{pH}=11\right)$

Figure 8 Consumption of sulfite $\left(\mathrm{SO}_{3}{ }^{2-}\right)$ with irradiation by a UV-L lamp with and without perchlorate $\left([\text { sulfite }]_{\text {initial }}=11 \mathrm{mM}\right.$, $[\text { perchlorate }]_{\text {initial }}=10 \mathrm{mg} / \mathrm{L} ; \mathrm{UV}-\mathrm{L}$ intensity $\left.=9.5 \mathrm{~mW} / \mathrm{cm}^{2}, \mathrm{pH}=11\right) \ldots$

Figure 9 Effect of wavelength of UV light on perchlorate reduction.

(a) perchlorate concentration profile and (b) sulfite concentration profile $\left([\text { perchlorate }]_{\text {initial }}=10 \mathrm{mg} / \mathrm{L} \text {, [sulfite }\right]_{\text {initial }}=11 \mathrm{mM}$;

$\mathrm{UV}-\mathrm{KrCl}$ and $\mathrm{UV}-\mathrm{L}$ intensity $=8.5 \mathrm{~mW} / \mathrm{cm}^{2}, \mathrm{pH}=11$ )

Figure 10 Effect of NOM on removal of perchlorate $\left(\mathrm{ClO}_{4}{ }^{-}\right)$with sulfite and irradiation by a UV-KrCl lamp ([perchlorate $]_{\text {initial }}=10 \mathrm{mg} / \mathrm{L}$, ssulfite $_{\text {initial }}=11 \mathrm{mM}$; UV-KrCl lamp intensity $=13 \mathrm{~mW} / \mathrm{cm}^{2}$, $\mathrm{pH}=11)$ 
Figure 11 Loss of NOM-absorbance during irradiation by a UV-KrCl lamp under different conditions $([\mathrm{NOM}]=50 \mathrm{mg} / \mathrm{L}$ as carbon, $[\text { perchlorate }]_{\text {initial }}=10 \mathrm{mg} / \mathrm{L}$, $[\text { sulfite }]_{\text {initial }}=11 \mathrm{mM}$;

$\mathrm{UV}-\mathrm{KrCl}$ lamp intensity $=13 \mathrm{~mW} / \mathrm{cm}^{2}, \mathrm{pH}=11$ )

Figure 12 Loss of sulfite by irradiation with a UV-KrCl lamp under different conditions ([perchlorate $]_{\text {initial }}=10 \mathrm{mg} / \mathrm{L}$, $[\text { sulfite }]_{\text {initial }}=11 \mathrm{mM},[\mathrm{NOM}]=50 \mathrm{mg} / \mathrm{L}$ as carbon; $\mathrm{UV}-\mathrm{KrCl}$ lamp intensity $=13 \mathrm{~mW} / \mathrm{cm}^{2}, \mathrm{pH}=11$ )

Figure 13 Effect of NOM on removal of perchlorate $\left(\mathrm{ClO}_{4}{ }^{-}\right)$with the Sulfite $/ U V-L$ ARP $\left([\text { perchlorate }]_{\text {initial }}=10 \mathrm{mg} / \mathrm{L}\right.$, [sulfite $]=11 \mathrm{mM}$; $\mathrm{UV}-\mathrm{L}$ intensity $\left.=9.5 \mathrm{~mW} / \mathrm{cm}^{2}, \mathrm{pH}=11\right)$

Figure 14 Loss of NOM with UV-L lamp under different conditions $\left([\mathrm{NOM}]=50 \mathrm{mg} / \mathrm{L}\right.$ as carbon, $[\text { perchlorate }]_{\text {initial }}=10 \mathrm{mg} / \mathrm{L}$, $[\text { sulfite }]_{\text {initial }}=11 \mathrm{mM}$; UV-L intensity $\left.=9.5 \mathrm{~mW} / \mathrm{cm}^{2}, \mathrm{pH}=11\right) \ldots \ldots \ldots \ldots$.

Figure 15 Absorbance spectra for different concentrations of NOM from $210 \mathrm{~nm}$ to $300 \mathrm{~nm}(\mathrm{pH}=11)$

Figure 16 Loss of sulfite with UV-L lamp under different conditions

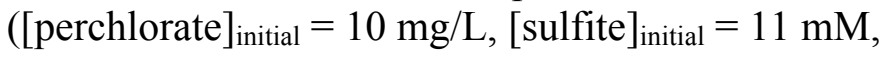
$[\mathrm{NOM}]=50 \mathrm{mg} / \mathrm{L}$ as carbon; UV-L lamp intensity $=9.5 \mathrm{~mW} / \mathrm{cm}^{2}$, $\mathrm{pH}=11$ ) 


\section{LIST OF TABLES}

Page

Table 1 Quantum yield ( $\phi_{\text {sulfite }}$ ) for sulfite loss during $\mathrm{UV}-\mathrm{KrCl}$ irradiation with and without perchlorate $([$ sulfite $]=11 \mathrm{mM}$, [perchlorate $_{\text {initial }}=10 \mathrm{mg} / \mathrm{L} ; \mathrm{UV}-\mathrm{KrCl}$ lamp intensity $=13 \mathrm{~mW} / \mathrm{cm}^{2}$, $\mathrm{pH}=11)$

Table 2 Quantum yield ( $\left.\phi_{\text {sulfite }}\right)$ for sulfite loss during UV-L irradiation with and without perchlorate ([sulfite $]_{\text {initial }}=11 \mathrm{mM}$, $[\text { perchlorate }]_{\text {initial }}=10 \mathrm{mg} / \mathrm{L}$; UV-L lamp intensity $=9.5 \mathrm{~mW} / \mathrm{cm}^{2}$, $\mathrm{pH}=11)$

Table 3 Pseudo-first-order rate constant $\left(\mathrm{k}_{\mathrm{obs}}\right)$ and $\mathrm{R}^{2}$ values for perchlorate removal at different concentrations of NOM

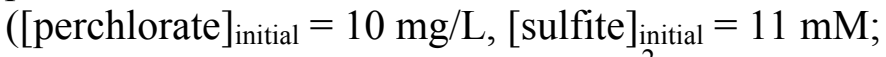
$\mathrm{UV}-\mathrm{KrCl}$ lamp intensity $=13 \mathrm{~mW} / \mathrm{cm}^{2}, \mathrm{pH}=11$ )

Table 4 Quantum yield ( $\phi_{\text {sulfite }}$ ) for loss of sulfite by irradiation with a UV-KrCl lamp under different conditions

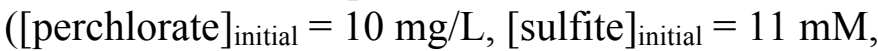
$[\mathrm{NOM}]=50 \mathrm{mg} / \mathrm{L}$ as carbon; UV-KrCl lamp intensity $=13 \mathrm{~mW} / \mathrm{cm}^{2}$, $\mathrm{pH}=11)$

Table 5 Pseudo-first-order rate constant $\left(\mathrm{k}_{\mathrm{obs}}\right)$ and $\mathrm{R}^{2}$ values for perchlorate removal in the presence of NOM ([perchlorate $]_{\text {initial }}=10 \mathrm{mg} / \mathrm{L}$, $[\text { sulfite }]_{\text {initial }}=11 \mathrm{mM}$; UV-L lamp intensity $\left.=9.5 \mathrm{~mW} / \mathrm{cm}^{2}, \mathrm{pH}=11\right) \ldots$ 


\section{INTRODUCTION}

Emerging contaminants are a group of materials or chemicals that are not controlled by law or regulation, but may have definite or potential risks to the environment or human health. Perchlorate is one of the major emerging contaminants of concern and has been found in soil and water systems throughout the United States. The primary emission source of perchlorate is military operations, because perchlorate is often used in rocket solid propellants, mortars and flares $(1,2)$. It has been demonstrated that human exposure to perchlorate could result in several diseases, since perchlorate is chemically competing with iodide in the human body. However, slow redox kinetics of perchlorate extremely limits the reactivity of perchlorate even though it is thermodynamically a strong oxidant. Therefore, perchlorate is a highly persistent species, especially at room temperature (3). Additionally, EPA has not set regulatory levels of perchlorate in drinking water and only some guidance or reference levels exist (4).

Recently, an increasing number of scientists and environmental agencies have participated in substantial efforts to find cost-effective perchlorate treatment technologies to provide us a safe environment for our lives. The most widely applied treatment technology for perchlorate removal is ion exchange, which collects perchlorate on the ion exchange resins without any degradation. Additional treatment prior to disposal of the resins is needed. Moreover, high resin affinity for perchlorate will result

This thesis follows the style of Environmental Science \& Technology. 
in difficult regeneration, causing ion exchange treatment to be relatively expensive compared to other technologies. Biological treatment technologies, such as bioreactors and microbial fuel cells, are able to convert $\mathrm{ClO}_{4}{ }^{-}$to $\mathrm{Cl}^{-}$, which is a much less toxic anion. But the primary difficulty with bioremediation of perchlorate is the process of transferring the application from the laboratory to the field, since biological processes are susceptible to environmental conditions such as concentration of nutrients and other anions $(3,5)$.

A new set of treatment technologies are called advanced reduction processes (ARP), and they are similar in concept to advanced oxidation processes (AOP). Highly reactive reducing free radicals are produced by ARP using reagents and activating methods. These reactive free radicals may be able to accelerate the rate of perchlorate degradation and overcome the disadvantages of biological and physical treatment technologies. Many wastewater treatment plants are now disinfecting using ultraviolet light, which is also a primary activating method in ARPs. ARPs are promising treatment technologies for practical application.

However, in a real system, natural organic matter (NOM) is a problem, since it is a precursor to forming disinfection by-products (DBPs) that are harmful. NOM is a large group of organic compounds that comes from plants and animals in the environment. The absorbance of NOM at $254 \mathrm{~nm}$ is often used to characterize NOM and photolysis of NOM can occur when irradiated by ultraviolet light. Therefore, NOM may inhibit the ability of ARPs to degrade perchlorate and there is a need for more data to test the extent to which NOM inhibits perchlorate destruction $(6,7)$. 
Therefore, the goal of the this research is to obtain data on the influences of natural organic matter on destruction of perchlorate by the ARP using sulfite and ultraviolet light, in order to support development of the processes as a practical water treatment method. This research will compare the results of the perchlorate reduction experiments conducted with a UV-L lamp that produces light primarily at $254 \mathrm{~nm}$ and a narrow band $\mathrm{KrCl} \mathrm{UV}$ excimer lamp that produces light primarily at $222 \mathrm{~nm}$.

Objective 1. Develop analytical and experimental procedures

The analytical method for perchlorate should be sufficiently sensitive, accurate and precise to achieve the goals of this research. Procedures will be developed for analysis of perchlorate by ion chromatography and the method detection limit, accuracy and precision will be measured. Experimental procedures will be developed that should provide reproducible and reliable results.

Objective 2. Characterize impacts of NOM on perchlorate reduction by the sulfite/UV-L ARP and by the sulfite/UV-KrCl ARP

This objective will be achieved by conducting a set of perchlorate reduction experiments at optimal sulfite concentration and $\mathrm{pH}$ value that use $\mathrm{NOM}$, light intensity, and light wavelength $(222 \mathrm{~nm}, 254 \mathrm{~nm})$ as experimental variables. These experiments will be used to provide information for development of the processes as a practical water treatment method.

Objective 3. Develop kinetic model for perchlorate reduction by ARP process This objective will be achieved by analyzing results of kinetic experiments that combine UV-L and UV-KrCl irradiation with sulfite and NOM. To identify perchlorate 
degradation kinetics and characterize results of the batch reactor experiments, different reaction orders such as zero-order, first-order, and second-order will be applied to fit the data collected from kinetic experiments. The coefficients of the kinetic models will be obtained by conducting non-linear regressions and the sum of squared residuals will be used to evaluate the relative ability of the models to fit the data. Matlab and Excel will be used to conduct the nonlinear regressions. The effects of NOM and wavelength of light on rate coefficients will be evaluated. 


\section{BACKGROUNDS AND HISTORY}

\subsection{Perchlorate}

Most perchlorate has been detected in military and defense areas in the United States. Perchlorate is present in soil, surface water, ground water, and drinking water in 49 states in the United States. A survey in western Texas claimed that more than $80 \%$ of drinking water wells are contaminated with perchlorate (2).

Natural perchlorate comes from the atmosphere, especially in arid places. Formation of natural occurring perchlorate is not well understood $(1,4)$, but there is a theory of its origin that is currently accepted. The theory claims that perchlorate is generated by the reaction of chloride compounds from the sea or the land with atmospheric ozone (3).

On the other hand, man-made forms include perchloric acid and perchlorate salts. Among them, ammonium perchlorate is the one that is mostly widely used and the primary use in the United States since the mid-1940s has been for defense and military purposes. It was also reported "approximately 90 percent of perchlorate compounds are manufactured for use in defense activities and the aerospace industry." (2). The common applications of perchlorate are as an oxidizer in solid propellants, fireworks, explosives, signal flares, and other pyrotechnics $(1,2)$.

Figure 1 (8) shows that the distribution of perchlorate manufactures and users in the United States in 2003. The red dots represent the utilization of perchlorate 
throughout the whole country. Those manufacturing facilities are present in at least 44 states.

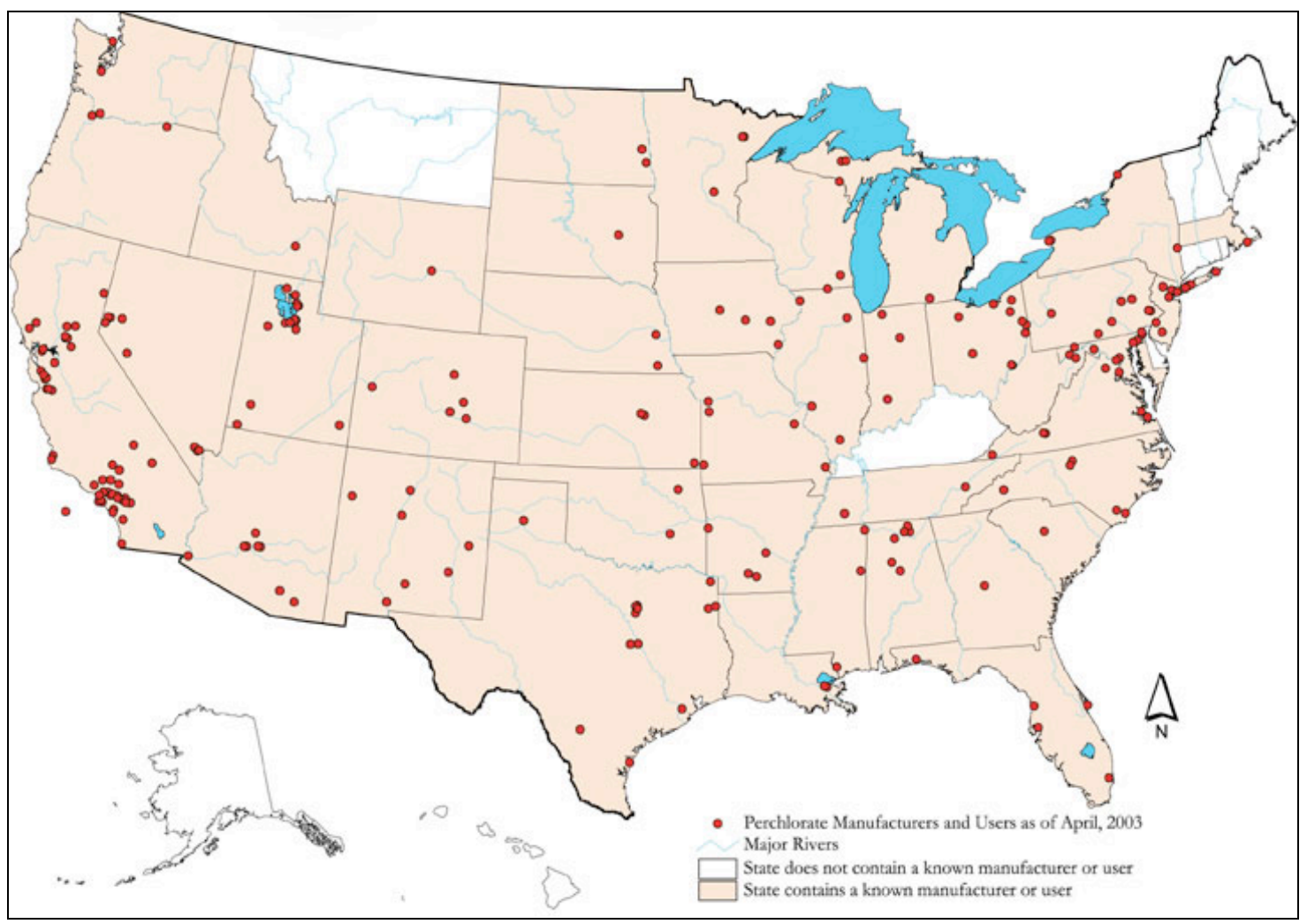

Figure 1. Perchlorate manufacturers and users in the United States as of April, 2003.

Source: U.S. EPA, 2003

Figure 2 (8) indicates locations where perchlorate has been released. These sites are potential sources of perchlorate that could contaminate water systems and soils.

Besides water and soil, perchlorate also has been detected in dairy products. Her et al. (9) recently found perchlorate in dairy milk and milk-based powdered infant formula in South Korea. They analyzed several different milk brands and found 
perchlorate at $1.99-6.41 \mu \mathrm{g} / \mathrm{L}$ in dairy milk and at $1.49-33.3 \mu \mathrm{g} / \mathrm{kg}$ in milk-based powdered infant formula. All these numbers exceed the limit of quantification for the relevant media $(0.12 \mu \mathrm{g} / \mathrm{L}$ for dairy milk, and $1.0 \mu \mathrm{g} / \mathrm{kg}$ for powdered milk).

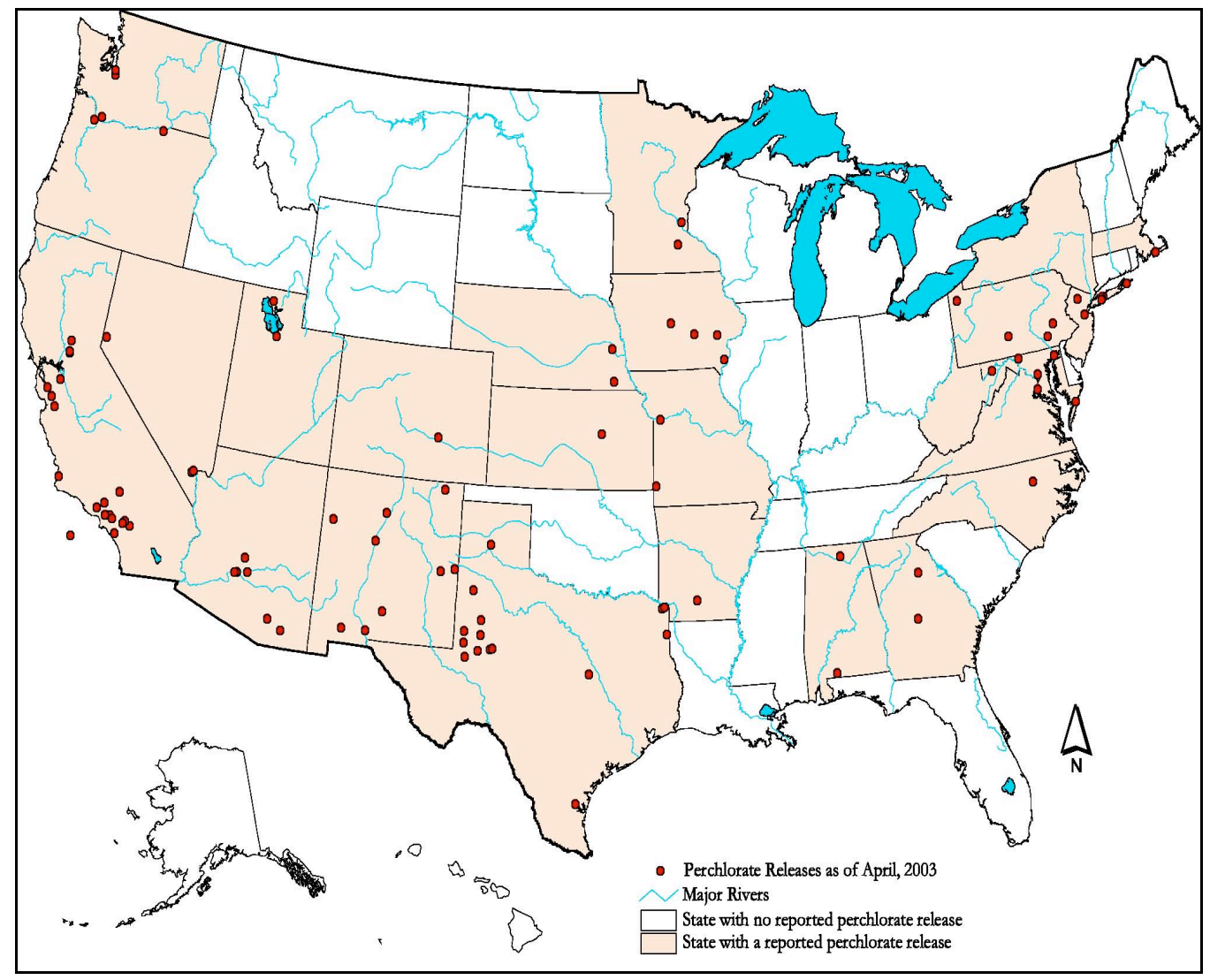

Figure 2. Perchlorate releases in the United States as of April, 2003.

Source: U.S. EPA, 2003

\subsubsection{Physical and Chemical Properties}

Perchlorate $\left(\mathrm{ClO}_{4}^{-}\right)$can associate with cations to form white crystalline solids, such as ammonium perchlorate $\left(\mathrm{NH}_{4} \mathrm{ClO}_{4}\right)$, sodium perchlorate $\left(\mathrm{NaClO}_{4}\right)$, and potassium 
perchlorate $\left(\mathrm{KClO}_{4}\right)(1,5)$. Additionally, perchloric acid $\left(\mathrm{HClO}_{4}\right)$ is a colorless liquid form of perchlorate (1). Perchlorate is highly soluble in water, particularly as sodium perchlorate. Its water solubility has been reported to be as high as $2096 \mathrm{~g} / \mathrm{L}$ at $25{ }^{\circ} \mathrm{C}$ and perchloric acid is miscible in cold water. Due to its poor ability to absorb onto mineral surfaces and organic material, perchlorate can move easily from soil to water. It is one of the weakest ligands in water $(1,3)$.

The structure of perchlorate anion is a chlorine atom surrounding by four oxygen atoms that are connected with polar bonds forming a tetrahedron (Figure 3) (10). The oxidation state of chlorine in the perchlorate anion is +7 . Thermodynamically, perchlorate is a strong oxidant, but it is generally considered to be a non-reactive compound at room temperature because of its slow redox kinetics (3).
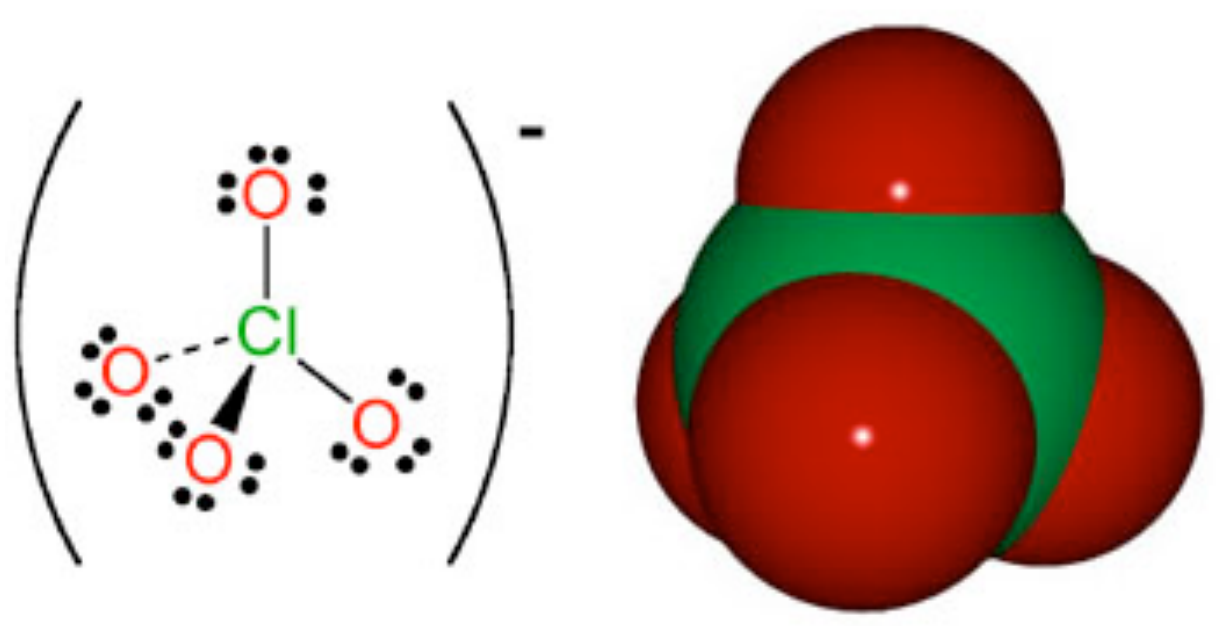

Figure 3. The structure of perchlorate anion.

Source: www.chemistry.wustl.edu 


\subsubsection{Toxicity and Regulation}

Ingestion of perchlorate can inhibit the uptake of iodine into the thyroid, where it is used to produce hormones that are needed for metabolic processes throughout the body $(3,11)$. The main mechanism is that the $\mathrm{ClO}_{4}{ }^{-}$blocks the sodium iodide symporter (NIS) protein, which is a pump on the surface of the thyroid follicle. Perchlorate acts as an inhibitor because iodide has a similar shape and electric charge as perchlorate. Besides the thyroid, the lactating breast epithelium, gastrointestinal tract, skin and mammary gland where the NIS protein exists may also be affected by perchlorate exposure (3). Human exposure to perchlorate can occur by eating contaminated food, drinking contaminated water, or by direct dermatological contact. For an adult, perchlorate exposure may lead to hypothyroidism. For infants or children whose bodily systems are still developing and therefore are more susceptible, the impairment is irreversible and may delay development and reduce the ability to learn. If pregnant and lactating women are exposed to perchlorate such that it results in low iodide uptake, their infants and children will also be adversely affected $(5,12)$.

Although perchlorate is widely present in soil, surface water, ground water, and drinking water and may result in human risk, there are no regulatory levels for perchlorate in drinking water (4). The concern over perchlorate dates back to March 2, 1998, when EPA put perchlorate on the first Contaminant Candidate List (CCL) and then included it on the second and third CCLs in 2005 and 2008, respectively (12). In 2005, EPA proposed an official reference dose $(\mathrm{RfD})$ of $0.7 \mu \mathrm{g} / \mathrm{kg} / \mathrm{day}$ by assuming that the uptake of perchlorate is from both water and food sources (13). This is consistent 
with the report of U.S. National Academy of Science in 2005 (13). The dose can also be translated to a value of $24.5 \mu \mathrm{g} / \mathrm{L}$ for the Drinking Water Equivalent Level (DWEL), which supposes that the contaminant is taken up only from drinking water (13). In 2008, U.S. EPA issued an interim health advisory level of $15 \mu \mathrm{g} / \mathrm{L}$ for drinking water. Maintaining concentrations at or under this level is believed to be protective of all subpopulations (14). Massachusetts and California were the first two states in United States to propose a perchlorate drinking water standard at $2 \mu \mathrm{g} / \mathrm{L}$ and $6 \mu \mathrm{g} / \mathrm{L}$ in 2006 and 2007, respectively (2). On February $11^{\text {th }}, 2011$, EPA's final determination indicates that perchlorate will be regulated with a National Primary Drinking Water Regulation (NPDWR) (12).

\subsection{Characteristics of Natural Organic Matter}

NOM is a complex mixture of organic compounds, including those that are largely aliphatic as well as those that are highly colored and aromatic. It is found in all surface, ground and soil waters, and it is a big problem in drinking water treatment processes, since NOM is responsible for adding odor and a brownish yellow color to the water. NOM also acts as the organic precursor for chlorination by-products $(6-7,15-16)$.

NOM can be classified into two components: hydrophobic NOM and hydrophilic NOM. Hydrophobic NOM is a humic substance, which can be removed by conventional treatment processes, while hydrophilic NOM is a non-humic substance, which is hard to remove (6).

Adsorption of UV light in wavelengths from 220 to $280 \mathrm{~nm}$ is one of the major measurements that are used for characterization of NOM. UV absorbance at $254 \mathrm{~nm}$ 
(UV254) is often used to determine the removal of $\operatorname{NOM}(7,17)$. Furthermore, specific UV-absorbance (SUVA) is also a common parameter for NOM characterization. SUVA is defined as the ratio of the absorbance of a given sample at $254 \mathrm{~nm}$ to the concentration of dissolved organic carbon of the sample. SUVA larger than $4 \mathrm{~L} / \mathrm{mg}-\mathrm{cm}$ means hydrophobic material is the main component, while SUVA smaller than $3 \mathrm{~L} / \mathrm{mg}-\mathrm{cm}$ indicates mainly hydrophilic substances present in the sample (7).

AOP is one of the most efficient methods for the removal of NOM. UVphotolysis at high doses can degrade NOM. A series of photochemical reactions occur when NOM is irradiated by UV light, which break the higher molecular weight fraction into smaller molecules that are available for further degradation $(17,18)$. Combination of UV light with hydrogen peroxide is much more efficient than UV light alone, since hydroxyl radicals are produced in that process, and hydroxyl radicals can also degrade NOM (15). Furthermore, it is reported that photo-Fenton's reagent (PFR) is the most effective AOP process for the removal of NOM compared to UV-C photolysis, UV$\mathrm{C} / \mathrm{H}_{2} \mathrm{O}_{2}$, and Fenton's reagent (FR) (17).

\subsection{Analytical Methods for Perchlorate}

The primary method that is used to detect perchlorate is ion chromatography (IC) and the method was developed by EPA in 1999. It is known as EPA Method 314.0 and it includes cleanup procedures to cope with interfering ions. This method is available for analysis of perchlorate in a wide range of different media - reagent water, surface water, groundwater, and finished drinking water. The detection limit (DL) for perchlorate in drinking water is $0.53 \mu \mathrm{g} / \mathrm{L}$ with an achievable minimum reporting level (MRL) of 4 
$\mu \mathrm{g} / \mathrm{L}$ (19). This is also the method that will be used in this research to quantitatively analyze perchlorate.

There are also many other methods that are applicable to the identification and quantitation of perchlorate in different matrices or are able to greatly reduce analytical times. EPA Method 332.0 is the combination of IC with suppressed conductivity and electrospray ionization/mass spectrometry (IC-ESI/MS) and can be applied to quantitate $\mathrm{ClO}_{4}{ }^{-}$in raw and finished drinking waters. The reported lowest MRL and DL of Method 332.0 is $0.10 \mu \mathrm{g} / \mathrm{L}$ and $0.02 \mu \mathrm{g} / \mathrm{L}$, respectively, which are much lower than that of Method 314.0. This method can handle a sample with a relatively high level of total dissolved solids. However, inlet fouling will deteriorate the signal intensity (20). A field screening method was proposed by U.S. Army Corps of Engineers for perchlorate analysis in water and soil by utilizing solid-phase extraction and a battery-operated spectrophotometer. The DL in this method is $1 \mu \mathrm{g} / \mathrm{L}$ for water and $0.4 \mathrm{mg} / \mathrm{kg}$ for soil (21). Method 6850 — high performance liquid chromatography/electrospray ionization/mass spectrometry (HPLC/ESI/MS or HPLC/ESI/MS/MS) has multiple media applications, such as water samples (including surface water, groundwater, wastewater, and salt water), soil samples and solid wastes samples, with the corresponding practical quantitation limits (PQL) of $0.2 \mu \mathrm{g} / \mathrm{L}, 2 \mu \mathrm{g} / \mathrm{L}$ and $6 \mu \mathrm{g} / \mathrm{L}$, respectively. The samples must go through the aqueous extraction step to separate $\mathrm{ClO}_{4}{ }^{-}$from other ions first, and then it can be determined (22). 


\subsection{Treatment Techniques}

\subsubsection{Current Treatment Technologies}

Conventional water treatment plants currently are not effective in removing perchlorate (23). But scientists are developing various treatment technologies to remove perchlorate from water, soil, and other media to reduce environmental risks. These technologies include commonly used bioreactors, ion exchange columns, and adsorption columns. Some of these processes convert perchlorate to a non-toxic form, while some only remove it from solution so that it continues to have the potential to pollute the environment.

A bioreactor is a treatment method that reduces perchlorate in water. Critical bacteria that can biodegrade perchlorate in water and soil are characterized as facultative anaerobes, and include the genera Dechloromonas, Dechlorospirillum and Azospira (formerly Dechlorosoma). They use $\mathrm{ClO}_{4}{ }^{-}$as a terminal electron acceptor, while organic substrates, hydrogen gas or sulfur compounds are acting as electron donors $(3,5$, and 24). 


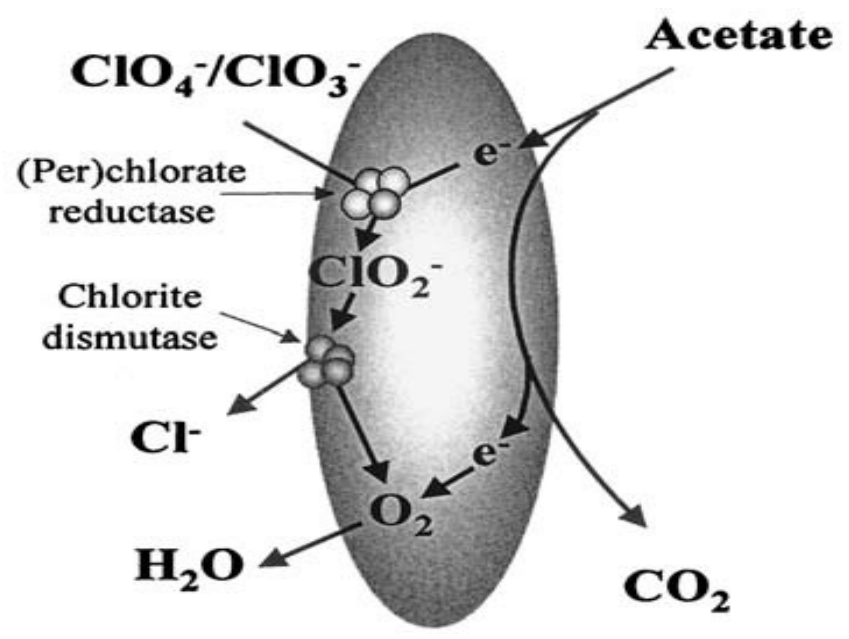

Figure 4. Schematic of biological reduction of perchlorate.

Source: Achenbach, et al., 2006

Packed bed reactors (PBR), fluidized bed reactors (FBR), continuous-flow stirred-tank reactors (CSTR) are three common types of bioreactors that are used for perchlorate removal. A PBR is a widely used fixed-film bioreactor and often consists of coarse sand, plastic, or other solid media on which target microorganisms grow $(3,5)$. Degradation of perchlorate by the organisms occurs as the contaminated water flows through this media $(5,23)$. A FBR is the most frequently used reactor type and was used in $37 \%$ of all ex situ biological case studies, while PBRs were used in $22 \%$ of the studies (23). Just like a PBR, a FBR is a fixed-film bioreactor with solid media to support bacterial activity, but the media particles are stationary and are not suspended in the fluid. Nutrients and ethanol are often added as electron donors to both types of reactors $(3,5)$. A CSTR is one of the most commonly used bioreactors and it performs well for low flow rates and high-concentration industrial wastes and represents $31 \%$ of all ex situ 
biological case studies (23). In contrast to the PBR and FBR, the CSTR is a completely mixed suspended-growth reactor. Therefore, all of the biomass is suspended and support media is not used. The concentration of biomass is the same anywhere in the tank, but the concentration is relatively low compared to fixed-film systems (5).

So far, the primary difficulty of most bioremediation techniques for perchlorate is the transfer of the application from the laboratory to the field, since biological processes are susceptible to environmental conditions such as concentration of nutrients and other anions that may be different in the large-scale application. A CSTR is limited in its ability to treat high flow rates (>1000 gallons per minute) and low-strength groundwater (23). PBRs need periodic backwashing to avoid clogging, and backwashing may impair the ability of the biomass to degrade $\mathrm{ClO}_{4}{ }^{-}(5,23)$. FBRs are now commercialized, but they are more expensive and operation is more complex compared to PBRs $(3,5)$.

Ion exchange is a full-scale physical technology and is the most commonly used and the most applicable technology for the reduction of perchlorate. Even lightly contaminated water could be treated. The ion exchange resin, such as polystyrenic resin, is one of the most vital components of the process and must have a strong affinity for $\mathrm{ClO}_{4}{ }^{-}$relative to other anions, so that $\mathrm{ClO}_{4}{ }^{-}$will replace the original anion associated with the resin. However, the higher the affinity is, the more difficult it is to regenerate the resin, which will result in difficulty in reusing the resin. The primary problems of ion exchange are the regeneration, costs, slow kinetics, and the interference of other anions present in the water, such as sulfate, nitrate, and bicarbonate $(3,5$, and 26$)$. 
Adsorption is a physical method that uses a specific adsorbent to remove perchlorate. Modified activated carbon (such as tailored granular activated carbon) is an effective adsorbent. It can be regenerated via a thermal process and the cost is lower than ion exchange (27).

Both ion exchange and adsorption are effective technologies, but they are only collecting perchlorate rather than destroying it, and additional treatment prior to disposal of the resins is needed. Thus, they have the potential to pollute the environment again if they are not disposed or reused properly (23).

\subsubsection{Advanced Reduction Processes}

Chemical reduction is widely used for treatment of environmental contaminants. Various types of reductants are able to convert perchlorate to chloride or chlorate, including $\mathrm{Fe}^{0}$, Ti (III), Cr (II), V (II), Re (V), and Mo (III) (28).

A study using elemental iron nanoparticles with microwave heating achieved $98 \%$ reduction of perchlorate in one hour at $200{ }^{\circ} \mathrm{C}$, while only $50.8 \%$ of perchlorate was reduced in 3 weeks at room temperature. Comparison with a block heater study indicates that temperature should be the only factor that affects perchlorate reduction by elemental iron (29). Im et al. (30) studied the impact of oxygen and UV radiation on

perchlorate removal by elemental iron. In a system with only $\mathrm{Fe}^{0}$-only, it was observed that approximately $100 \%$ of perchlorate was removed in 9 hours in the presence of oxygen, while only $2 \%$ of perchlorate was removed in 12 hours under anoxic conditions. The reason for this phenomenon could be the fast iron oxidation under oxic conditions and formation of iron oxides that could sorb or co-precipitate perchlorate to enhance the 
removal. However, with the irradiation of ultraviolet light, only $40 \%$ and $5.6 \%$ of initial perchlorate was reduced under oxic and anoxic conditions, respectively. The slower perchlorate reduction under oxic conditions and with UV radiation is due to formation of the hydroxyl radical, which is an inhibitor for perchlorate removal in the $\mathrm{Fe}^{0} / \mathrm{H}_{2} \mathrm{O}$ system (30).

Utilization of a catalyst has been reported to be an effective way to completely reduce perchlorate to chloride (31-33). A heterogeneous catalyst containing $\mathrm{Re}-\mathrm{Pd} / \mathrm{C}$ was prepared by the combination of a precursor, such as the complex chlorobis (2-(2'hydroxyphenyl)-2-oxazoline)-oxorhenium (V), Re (O)(hoz) $)_{2} \mathrm{Cl}$, with 5\% Pd-activated carbon powder. Hydrogen gas could effectively reduce perchlorate to chloride within few hours under acidic conditions in the presence of this catalyst at room temperature $(31,32)$. It was also been reported that adding pyridine compounds as ligands into the catalyst with the perrhenate ion could improve activity and stability of the catalytic system (33). Titanium (III) is another catalyst that has been studied and the results indicate that relatively higher initial concentrations of perchlorate are removed more effectively. Additionally, the rate of perchlorate reduction catalyzed by titanium could be increased by several orders of magnitude if the media is ethanol rather than water (28).

Slow rates of reduction and the requirement of high activation energy are the primary limitations associated with conventional chemical reduction processes. However, a group of treatment processes that produce highly reactive reducing species in a manner analogous to AOPs that produce highly reactive oxidizing species (34), would be able to avoid these kinetic limitations. The mechanism of AOPs is the 
formation of the hydroxyl radical $\left(\mathrm{HO}^{\circ}\right)$, which is a highly reactive oxidant that can destroy contaminants at ambient temperature and atmospheric pressure. Technologies that have been used to generate hydroxyl radicals include ozone with UV light, ozone with hydrogen peroxide, hydrogen peroxide with UV light, and titanium dioxide with UV light $(34,35)$.

Our laboratory has developed a new group of treatment processes that are similar to AOPs and they are called ARPs. ARPs produce reductive free radicals by combining reductants and activating methods. They have the potential to treat oxidized contaminants, such as perchlorate, chlorinated organics, chromate, bromate, nitrate, arsenate, selenite, and a number of radionuclides. Reductive free radicals can donate an unpaired electron to the target contaminant being reduced. The reductants that can be used for ARPs include dithionite, sulfite, sulfide, and ferrous ion, while the activating methods include UV light, electron beam, ultrasound, and microwave. The results of a discovery project in our laboratory indicate that the combination of sulfite with ultraviolet light produced by low-pressure mercury lamps (UV-L, $254 \mathrm{~nm}$ ) is the most effective and promising way to remove perchlorate.

Sulfite is a commercially applied bleaching agent and can be used in water treatment processes. Sulfite irradiated by UV light will produce sulfite radicals and aqueous electrons, which are much more reactive than sulfite itself (36). Sulfite solutions absorb UV light with a maximum absorbance around $200 \mathrm{~nm}$ (37). The absorbance of a sulfite solution at $222 \mathrm{~nm}$ is much higher than that at $254 \mathrm{~nm}$ (37). Theoretically, more 
sulfite radicals will be generated with a $222 \mathrm{~nm}$ UV lamp and will result in a more rapid perchlorate process. 


\section{EXPERIMENTAL METHODS AND MATERIALS}

\subsection{Reaction Apparatus}

\subsubsection{UV Lamps}

One UV light source is from Phillips (Phillips Model TUV PL-L36W/4P) and it emits short-wave UV radiation with a peak at $253.7 \mathrm{~nm}$. The other source is a $\mathrm{KrCl}$ excimer lamp from the Institute of High Current Electronics, SB Russian Academy of Science and produces short-wave UV radiation with a peak at $222 \mathrm{~nm}$. The light intensity at the top of the reactor with both light sources was measured with a UV digital light meter (General, Model No. UV 512C), which was calibrated by ferrioxalate actinometry (Appendix A).

\subsubsection{Anaerobic Chamber}

All irradiation experiments and related work were conducted in an anaerobic chamber (Coy Laboratory Products Inc.) that was filled with a gas mixture $(95 \%$ nitrogen and 5\% hydrogen, Acetylene Oxygen Company) and equipped with an analyzer for oxygen and hydrogen, fan boxes and a palladium catalyst STAK-PAK (Coy Laboratory Products Inc.) that scavenges oxygen. The anaerobic chamber is vacuumed and refilled with the gas mixture twice a week or as required to keep the anaerobic condition inside the chamber. 


\subsubsection{Reactors}

All UV irradiation experiments were carried out in 17-mL, cylindrical, UVtransparent quartz reactors (Starna cells, Inc.). Their exterior diameter is $50 \mathrm{~mm}$ and their light path length is $10 \mathrm{~mm}$.

\subsection{Reagent}

\subsubsection{Deoxygenated Deionized Water}

The deionized (DI) water (Milli-Q, Millipore) used in all experiment was deoxygenated by sparging with ultra high purity (UHP) nitrogen (Acetylene Oxygen Company) for 2 hours, and then sparged with a gas mixture (95\% nitrogen and 5\% hydrogen, Acetylene Oxygen Company) for 24 hours.

\subsubsection{Perchlorate Standards}

A $0.3-\mathrm{mL}$ volume of a $997 \pm 20 \mu \mathrm{g} / \mathrm{mL}$ perchlorate standard (Inorganic Ventures, Inc.) and $30 \mathrm{~mL}$ of DI water were added into a 50-mL centrifuge tube with screw caps (VWR International, LLC.) to obtain a perchlorate solution with a concentration of 10 mg/L. The centrifuge tube was placed on a mixer (Scientific Industries, Inc., VORTEXGENIE $\left.^{\mathrm{TM}} \mathrm{K}-550-\mathrm{G}\right)$ until the solution was well mixed. The $10 \mathrm{mg} / \mathrm{L}$ perchlorate solution was diluted with DI water to concentrations of $1,2.5,5$, and $7.5 \mathrm{mg} / \mathrm{L}$. These 5 levels (1, $2.5,5,7.5$, and $10 \mathrm{mg} / \mathrm{L}$ ) were used to develop a calibration curve.

\subsubsection{Sodium Sulfite}

Approximately 1 gram of anhydrous sodium sulfite (98.6\%, J.T. Baker) and 20 $\mathrm{mL}$ of deoxygenated DI water were added into a $50-\mathrm{mL}$ centrifuge tube inside the anaerobic chamber. The centrifuge tube with the well-mixed sodium sulfite solution was 
placed in a box in the anaerobic chamber to avoid irradiation before use. Sodium sulfite stock solution was considered usable only for one day and was re-prepared when experiments were conducted on different days.

The stock sodium sulfite solution was diluted with deoxygenated DI water to concentrations of $2,4,6,8,10$, and $12 \mathrm{mM}$. These 6 levels of sodium sulfite were used to develop a calibration curve.

\subsubsection{Potassium Hydrogen Phosphate Stock Solution}

Approximately 17.418 gram of anhydrous potassium hydrogen phosphate $(98 \%$, Alfa Aesar) was dissolved in $100 \mathrm{~mL}$ of deoxygenated DI water inside the anaerobic chamber to produce a $1 \mathrm{M} \mathrm{K}_{2} \mathrm{HPO}_{4}$ stock solution and that was stored in a box in the anaerobic chamber before use.

\subsubsection{Suwannee River Natural Organic Matter}

Approximately 0.0953 gram of Suwannee River natural organic matter powder (International Humic Substances Society, Catalog No. 1R101N, RO isolation) and 500 $\mathrm{mL}$ of deoxygenated DI water were added into a $500-\mathrm{mL}$ volumetric flask inside the anaerobic chamber. The carbon elemental composition in of the dry, ash-free Suwannee River NOM is $52.47 \%(\mathrm{w} / \mathrm{w})$. The solution was well mixed and stored in an amber bottle (VWR International, LLC.) in a box in the anaerobic chamber before use.

The stock NOM solution (100 mg/L carbon) was diluted with deoxygenated DI water to concentrations of $10,15,30,45$, and $60 \mathrm{mg} / \mathrm{L}$ as carbon. These 5 levels of NOM were used to develop a calibration curve. 


\subsubsection{Sodium Hydroxide Stock Solution}

A 5-mL volume of a $10 \mathrm{~N}$ sodium hydroxide solution (J.T. Baker) and $45 \mathrm{~mL}$ of deoxygenated DI water were added into a 50-mL centrifuge tube inside the anaerobic chamber. The well-mixed sodium hydroxide solution with concentration of $1 \mathrm{~N}$ was placed in a box in the anaerobic chamber to avoid irradiation before use.

\subsection{Experimental Procedures}

\subsubsection{Constant Conditions}

The initial concentration of perchlorate in all experiments was about $10 \mathrm{mg} / \mathrm{L}$ (approximately $0.1 \mathrm{mM}$ ) and the initial sulfite concentration was approximately $11 \mathrm{mM}$, which is 100 times over the stoichiometric amount needed to reduce perchlorate to chloride. The $\mathrm{pH}$ value of the solution was adjusted to $\mathrm{pH} 11$ by using $1 \mathrm{~N}$ potassium hydrogen phosphate and $1 \mathrm{~N}$ sodium hydroxide. The light intensity was measured at the

beginning and the end of each experiment and was set between 8.0 and $13.0 \mathrm{~mW} / \mathrm{cm}^{2}$ by adjusting the distance between the reactor and the lamp.

\subsubsection{Variable Conditions}

NOM and lamp wavelength were experimental variables and their effects on perchlorate reduction were investigated. The concentrations of NOM that were studied are $2.5,5,10,30$, and $50 \mathrm{mg} / \mathrm{L}$ as $\mathrm{C}$. The $\mathrm{UV}$ wavelengths that were investigated are $222 \mathrm{~nm}$ and $254 \mathrm{~nm}$.

\subsubsection{Kinetic Experiments}

All the kinetic experiments were conducted inside the anaerobic chamber. A 1.5$\mathrm{mL}$ volume of a $997 \pm 20 \mu \mathrm{g} / \mathrm{mL}$ perchlorate standard (Inorganic Ventures, Inc.), $0.75 \mathrm{~mL}$ 
of $1 \mathrm{~N}$ potassium hydrogen phosphate stock solution, $75 \mathrm{~mL}$ of $100 \mathrm{mg}$ C/L NOM stock solution, and $72.75 \mathrm{~mL}$ of deoxygenated DI water were added into a $200-\mathrm{mL}$ beaker to produce a solution with a perchlorate concentration of $10 \mathrm{mg} / \mathrm{L}$ and a NOM concentration of $50 \mathrm{mg} / \mathrm{L}$ as $\mathrm{C}$. The $\mathrm{pH}$ value of the solution was adjusted to 11 by adding $1 \mathrm{~N}$ sodium hydroxide slowly. These steps were repeated, but with different NOM concentrations $(0,2.5,5,10$, and 30$)$ and different types of UV light (222 nm and $254 \mathrm{~nm})$.

A $15-\mathrm{mL}$ initial solution was transferred to each quartz reactor by the pipette. This was done by holding the side of the quartz reactors to avoid adding fingerprints or dirt to the surface of the reactors through which light would pass. Seven reactors were prepared for each of the experiments that use the low pressure UV lamp (254 nm). UV light irradiated the reactors for a time period of 25 hours. One reactor was removed and analyzed every 2 to 4 hours at the beginning of the experiment, but the time between samples increased to 9 to 12 hours toward the end of the experiment. The reactors were stored in a black box inside the chamber before analysis. For experiments conducted with the narrow band $\mathrm{KrCl} \mathrm{UV}$ excimer lamp (222 nm), five reactors were taken for analysis every 2 or 4 hours, and the last one was taken after 9 hours of irradiation.

\subsection{Analytical Methods}

Ion chromatography using a Dionex DX 500 IC with a CD 20 Conductivity Detector and GP40 Gradient Pump was adopted to analyze perchlorate in this research. Before the analysis of perchlorate in samples with NOM, the samples were passed through a $0.45-\mu \mathrm{m}$ cellulose nitrate membrane filter $(25 \mathrm{~mm}$-diameter, Whatman) and 
collected in 0.5-mL vials (Dionex) with caps. The samples contained in these vials were analyzed by an ion chromatograph equipped with AS-16 column and AS40 automated sampler following Standard Method 4110 (38). The following parameters were used during analysis: applied current of $100 \mathrm{~mA}, \mathrm{NaOH}$ eluent concentration of $40 \mathrm{mM}$, flow rate of $1.0 \mathrm{~mL} / \mathrm{min}$, pressure of $8-10$ psia, and sample loop size of $200 \mu 1$. The average recovery (accuracy) was $96.1 \%$ and the relative standard deviation (precision) was 2.96 $\%$. The average method detection limit (MDL) for perchlorate was $0.038 \mathrm{mg} / \mathrm{L}$. A UV-Visible spectrophotometer (He $\lambda$ ios, Thermo Spectronic) was used to measure the concentration of sulfite and NOM. A standard curve was developed to show the relationship between absorbance at $240 \mathrm{~nm}$ and the concentration of sulfite $(2,4,6$, 8,10 , and $12 \mathrm{mM}$ ). NOM also absorbs light at this wavelength, so a procedure was developed to correct for this. Figure Appendix B.1 shows that NOM and sulfite both absorb at wavelengths between $210 \mathrm{~nm}$ to $260 \mathrm{~nm}$. However, the absorbance of sulfite is negligible compared to the absorbance of NOM at $270 \mathrm{~nm}$. Therefore, the absorbance at $270 \mathrm{~nm}$ of a mixed solution (NOM and sulfite) was used to characterize the condition of NOM. The absorbance at 240 was used to measure sulfite concentration, but it was corrected for the absorbance due to NOM. The absorbance at $240 \mathrm{~nm}$ due to NOM was estimated by measuring the absorbance at $270 \mathrm{~nm}$, calculating NOM concentration with a calibration curve and then calculating the absorbance due to NOM at $240 \mathrm{~nm}$ with another calibration curve. These calibration curves were determined over a range of NOM concentrations $(10,15,30,45$, and $60 \mathrm{mg} / \mathrm{L}$ as $\mathrm{C})$. 


\section{CHARACTERISTICS OF PERCHLORATE REDUCTION BY ARP}

\subsection{Perchlorate Reduction by Sulfite/UV-KrCl ARP}

Figure 5 shows results of experiments on perchlorate reduction by the sulfite/UV-KrCl ARP. Perchlorate was barely removed either by sulfite without UV irradiation or by UV irradiation without sulfite in $\mathrm{pH}$-buffered solution after 25 hours. But, with both sulfite and UV irradiation, perchlorate removal was significantly improved. More than $50 \%$ of perchlorate was removed after 9 hours by the combination of sulfite and narrow band $\mathrm{KrCl} \mathrm{UV}$ excimer ultraviolet lamp at base conditions (1 M potassium hydrogen phosphate buffer, $\mathrm{pH} 11$, adjusted by $1 \mathrm{M}$ sodium hydroxide). Figure 5 also shows the balance of chlorine in the ARP system. Approximately $20 \%$ of the original chlorine was found as chloride ion, with about $76 \%$ of the chlorine originally added being recovered. The rest of the chlorine may exist in the solution as chlorate or chlorite. 


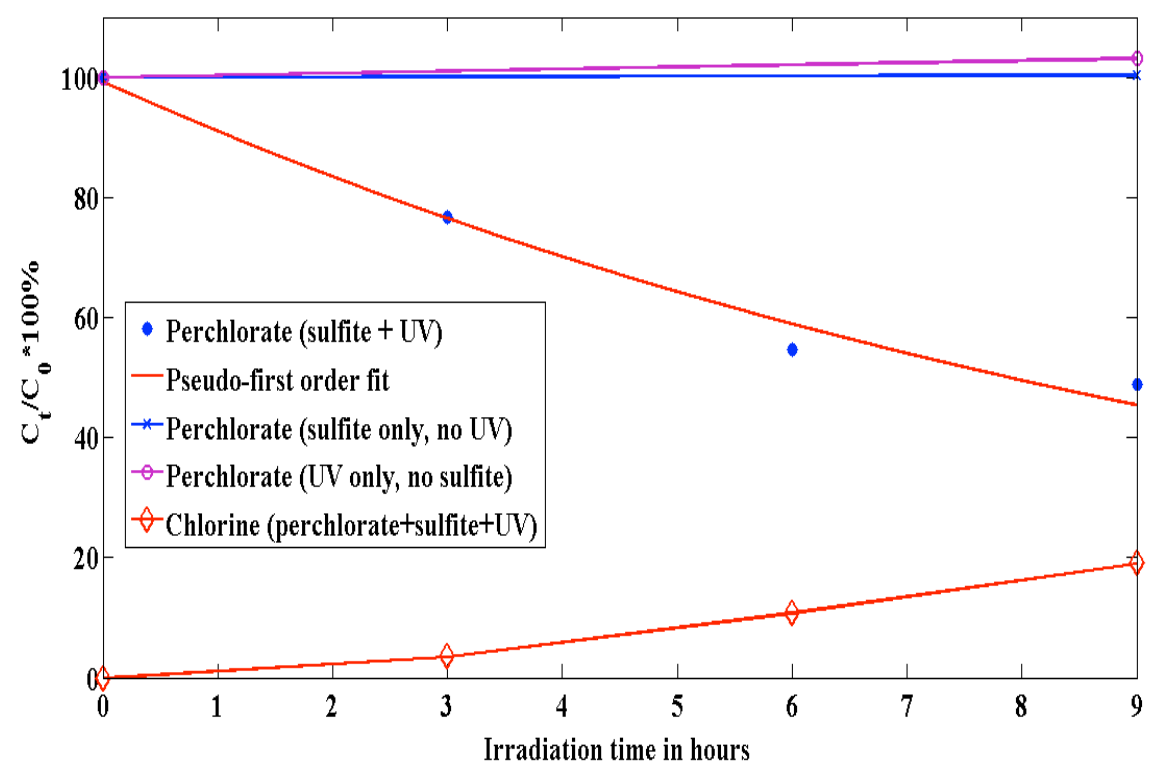

Figure 5. Removal of perchlorate $\left(\mathrm{ClO}_{4}^{-}\right)$and production of chloride ions $\left(\mathrm{Cl}^{-}\right)$ with and without sulfite and UV-KrCl lamp $\left([\text { perchlorate }]_{\text {initial }}=10 \mathrm{mg} / \mathrm{L},[\text { sulfite }]_{\text {initial }}=\right.$ $11 \mathrm{mM}$; UV-KrCl lamp intensity $\left.=13 \mathrm{~mW} / \mathrm{cm}^{2}, \mathrm{pH}=11\right)$.

It has been reported that UV irradiation of sulfite solution will generate hydrated electron and sulfite radical ion, which are highly reactive reducing radicals, although the sulfite radical anion can also be an oxidizing radical $(36,39-41)$. But without UV irradiation, sulfite cannot produce radicals by itself (36). Instead of producing the sulfite radical, Pemberton et al. (36) reported that irradiation of sulfite produces the sulfur dioxide radical $\left(\mathrm{SO}_{2}^{-}\right)$, which is a strong reducing radical.

One possible perchlorate removal mechanism can be described by the following equations. This mechanism is analogous to the mechanism for sulfite reacting with 
oxygen (42-44). The chlorate that is formed by reaction with the sulfite radical (Equation 2) then could be easily reduced to chloride ion (45).

$$
\begin{gathered}
\mathrm{SO}_{3}^{2-}+\mathrm{hv}=\mathrm{SO}_{3}^{--}+\mathrm{e}_{\mathrm{aq}}^{-} \\
\mathrm{SO}_{3}^{--}+\mathrm{ClO}_{4}^{-}=\mathrm{SO}_{4}^{--}+\mathrm{ClO}_{3}^{-} \\
\mathrm{SO}_{4}^{--}+\mathrm{e}_{\mathrm{aq}}^{-}=\mathrm{SO}_{4}^{2-} \\
\mathrm{SO}_{3}^{--}+\mathrm{e}_{\mathrm{aq}}^{-}=\mathrm{SO}_{3}^{2-}
\end{gathered}
$$

In order to analyze how rapidly perchlorate has been removed, the general firstorder decay model was applied. Combining a first-order rate equation with a material balance for a batch system gives Equation 5 .

$$
\frac{d C}{d t}=-\mathrm{k}_{o b s} \mathrm{C}
$$

where $\mathrm{k}_{\mathrm{obs}}\left(\mathrm{hr}^{-1}\right)$ is the pseudo-first-order rate constant, $\mathrm{C}(\mathrm{mg} / \mathrm{L})$ is the concentration of contaminant at specified time, $\mathrm{t}(\mathrm{hr})$. The pseudo-first-order rate constant was obtained by doing non-linear regression using Matlab (see Appendix C.1). The $\mathrm{k}_{\mathrm{obs}}$ for perchlorate removal by sulfite/UV-KrCl was estimated to be $0.087 \pm 0.039 \mathrm{hr}^{-1}\left(\mathrm{R}^{2}=0.98\right)$.

Figure 6 shows that about $100 \%$ of initial sulfite was consumed during a perchlorate reduction experiment after 9 hours. A similar percentage loss of sulfite was obtained in a sulfite-only experiment with irradiation by UV-KrCl lamp. Loss of sulfite will stop the perchlorate reduction processes. 


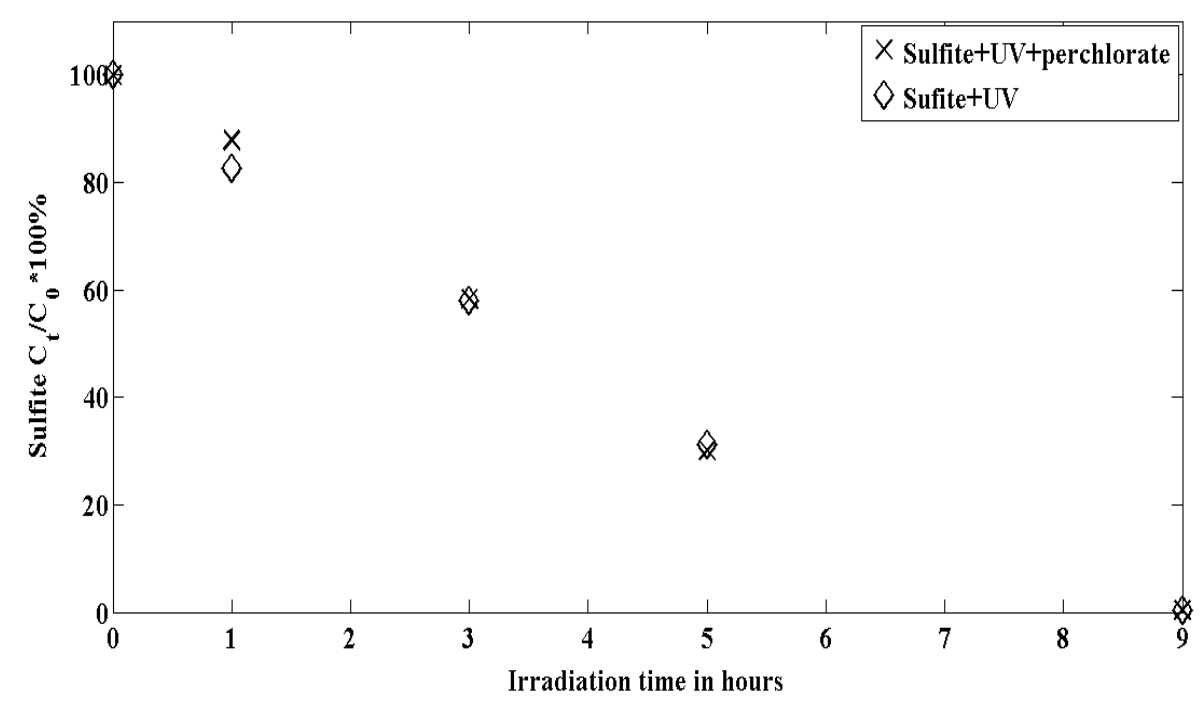

Figure 6. Consumption of sulfite $\left(\mathrm{SO}_{3}{ }^{2-}\right)$ with $\mathrm{UV}-\mathrm{KrCl}$ lamp with and without perchlorate $\left([\right.$ sulfite $]=11 \mathrm{mM},[\text { perchlorate }]_{\text {initial }}=10 \mathrm{mg} / \mathrm{L} ; \mathrm{UV}-\mathrm{KrCl}$ lamp intensity $=$ $\left.13 \mathrm{~mW} / \mathrm{cm}^{2}, \mathrm{pH}=11\right)$.

Absorption of UV light by a compound in aqueous solution can be described by Beer-Lambert law, as shown in Equation 6.

$$
\log \left(\frac{I}{I_{0}}\right)=-\varepsilon C x
$$

where $\mathrm{I}_{0}$ and $\mathrm{I}\left(\mathrm{einstein} / \mathrm{cm}^{2} / \mathrm{s}\right.$ ) are the light intensity at wavelength $\lambda$ entering and at a distance $\mathrm{x}$ into a solution; $\varepsilon(\mathrm{L} / \mathrm{mol} / \mathrm{cm})$ is the molar absorptivity at wavelength $\lambda$ of the light-absorbing solute in solution; $\mathrm{C}(\mathrm{mol} / \mathrm{L})$ is the concentration of light-absorbing solute, and $\mathrm{x}(\mathrm{cm})$ is the length of the light path through the solution. Equation 7 is a conversion of Equation 6 to base e: 


$$
\begin{aligned}
& \ln \left(\frac{I}{I_{0}}\right)=-\varepsilon^{\prime} C x \\
& \ln \left(\frac{I}{I_{0}}\right)=-\alpha^{\prime} x
\end{aligned}
$$

where $\varepsilon^{\prime}(\mathrm{L} / \mathrm{mol} / \mathrm{cm})$ is the base e molar absorptivity at wavelength $\lambda\left(\varepsilon^{\prime}=2.303 \varepsilon\right)$ and $\alpha^{\prime}\left(\mathrm{cm}^{-1}\right)$ is the absorption coefficient $\left(\alpha^{\prime}=\varepsilon^{\prime} \times C\right)$.

The rate of light absorption (einstein $/ \mathrm{cm}^{3} / \mathrm{s}$ ) by a compound, i, is proportional to light intensity (34):

$$
\begin{gathered}
r_{\text {light }, i}=\alpha_{i}^{\prime} I \\
r_{\text {light }, i}=\varepsilon^{\prime}{ }_{i} C_{i} I_{0} e^{-\alpha_{\text {all }}^{\prime} x}
\end{gathered}
$$

where $\alpha_{\text {all }}^{\prime}$ is the summation of absorption coefficients for water and all dissolved compounds that substantially absorb light $\left(\alpha_{\text {all }}^{\prime}=\alpha^{\prime}{ }_{\text {water }}+\sum \alpha_{i}^{\prime}=\alpha^{\prime}{ }_{\text {water }}+\sum \varepsilon^{\prime}{ }_{i} \mathrm{C}_{\mathrm{i}}\right)$.

Quantum yield ( $\phi$, mol/einstein) at wavelength $\lambda$ is defined as the proportionality factor between the rate of a reaction resulting from photolysis $\left(\mathrm{r}_{\mathrm{rxn}}, \mathrm{mol} / \mathrm{cm}^{3} / \mathrm{s}\right)$ and the rate of light absorption $\left(\mathrm{r}_{\text {light }}\right.$, einstein $\left./ \mathrm{cm}^{3} / \mathrm{s}\right)$.

$$
\begin{gathered}
\phi=-\frac{r_{r x n}}{r_{\text {light }}} \\
\phi=-\frac{r_{r x n}}{\varepsilon_{i}^{\prime} C_{i} I_{0} e^{-\alpha_{a l l}^{\prime} x}}
\end{gathered}
$$

Therefore, photolysis reaction rate for a compound at a point in reactor can be expressed as: 


$$
r_{r x n, i}=-\phi \varepsilon_{i}^{\prime} C_{i} I_{0} e^{-\alpha^{\prime}{ }_{a l l} x}
$$

If it is assumed that the contents in the reactor are completely mixed, then the average photolysis reaction rate $\left(\mathrm{mol} / \mathrm{cm}^{3} / \mathrm{s}\right)$ in the reactor can be obtained.

$$
\begin{gathered}
r_{r x n, i, a v g}=\left(\phi \varepsilon_{i}^{\prime} C_{i} I_{0} e^{-\alpha_{a l l}^{\prime} x}\right)_{a v g} \\
r_{r x n, i, a v g}=\phi \varepsilon_{i}^{\prime} C_{i} I_{a v g}
\end{gathered}
$$

where $I_{a v g}$ is the average light intensity that can be calculated by,

$$
\begin{gathered}
I_{\text {avg }}=\frac{\int_{0}^{L} I d x}{\int_{0}^{L} d x} \\
I_{\text {avg }}=\frac{\int_{0}^{L} I_{0} e^{-\alpha_{\text {all }}^{\prime} x} d x}{\int_{0}^{L} d x} \\
I_{\text {avg }}=\frac{I_{0}\left(1-e^{-\alpha_{\text {all }}^{\prime} x}\right)}{\alpha_{\text {all }}^{\prime} L}
\end{gathered}
$$

where $\mathrm{L}(\mathrm{cm})$ is the effective light path length through the reactor. Therefore, the final equation for photolysis reaction rate for a compound can be expressed as:

$$
r_{r x n, i, a v g}=\frac{\phi \varepsilon_{i}^{\prime} C_{i} I_{0}}{\alpha_{a l l}^{\prime} L}\left(1-e^{-\alpha_{a l l}^{\prime} L}\right)
$$

This rate equation can be combined with a material balance for a batch system to provide the following.

$$
\frac{d C_{i}}{d t}=\frac{\phi \varepsilon_{i}^{\prime} C_{i} I_{0}}{\alpha_{\text {all }}^{\prime} L}\left(1-e^{-\alpha_{\text {all }}^{\prime} L}\right)
$$


Light absorption by water and perchlorate is not significant compare to that of sulfite. Therefore, $\alpha^{\prime}{ }_{\text {all }}=\varepsilon^{\prime}$ sulfite $\mathrm{C}_{\text {sulfite, }}$, when sulfite is the only dissolved compound that substantially absorbs light. With this assumption, Equation 20 can be simplified.

$$
\frac{d C}{d t}=-\phi \frac{I_{0}}{L}\left(1-e^{-\varepsilon^{\prime} C L}\right)
$$

where $\mathrm{C}(\mathrm{mol} / \mathrm{L})$ is the concentration of sulfite at time $\mathrm{t}(\mathrm{hr})$.

The quantum yield for sulfite photolysis with UV light (Equation 1) was estimated by doing non-linear regression using Equation 21 and experimental data (see Appendix C.2). The effective light path for all experiments is $1 \mathrm{~cm}$. The light intensity, $\mathrm{I}_{\text {meas }}$, measured by UV meter was as an energy flux $\left(\mathrm{mW} / \mathrm{cm}^{2}\right)$, which can be converted to a photon flux (einstein $/ \mathrm{m}^{2} / \mathrm{s}$ ) by applying Planck's equation.

$$
I=I_{\text {meas }} \times \frac{\lambda}{N_{a} \times h \times c}
$$

where $\lambda(\mathrm{m})$ is the wavelength of UV light, $\mathrm{N}_{\mathrm{a}}$ is the Avogadro's number $6.02 \times 10^{23}$ $\left.\mathrm{mol}^{-1}\right), \mathrm{h}$ is Planck's constant $\left(6.626 \times 10^{-34} \mathrm{~J}-\mathrm{s}\right), \mathrm{c}$ is the speed of light $\left(3 \times 10^{8} \mathrm{~m} / \mathrm{s}\right)$.

The calculated values of quantum yield ( $\left.\phi_{\text {sulfite }}\right)$ for sulfite loss are shown in Table 1 . The quantum yields for the two experiments are very close, which indicates that perchlorate has no effect on loss of sulfite under UV-KrCl lamp irradiation. 
Table 1. Quantum yield ( $\left.\phi_{\text {sulfite }}\right)$ for sulfite loss during $\mathrm{UV}-\mathrm{KrCl}$ irradiation with

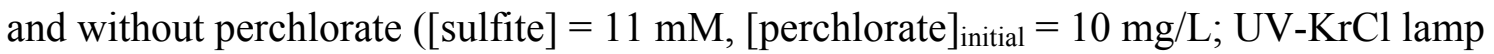

$$
\text { intensity } \left.=13 \mathrm{~mW} / \mathrm{cm}^{2}, \mathrm{pH}=11\right) \text {. }
$$

\begin{tabular}{cc}
\hline Experimental Conditions & $\phi_{\text {sulfite }}($ mol/einstein $)$ \\
\hline Sulfite/UV-KrCl & $0.018 \pm 0.0018$ \\
Sulfite/UV-KrCl/perchlorate & $0.016 \pm 0.0008$ \\
\hline
\end{tabular}

\subsection{Perchlorate Reduction by Sulfite/UV-L ARP}

Perchlorate was barely removed by only sulfite or by only UV-L after 25 hours (Figure 7). But with both sulfite and UV-L irradiation, more than $80 \%$ of initial perchlorate was removed after 25 hours at base conditions. 


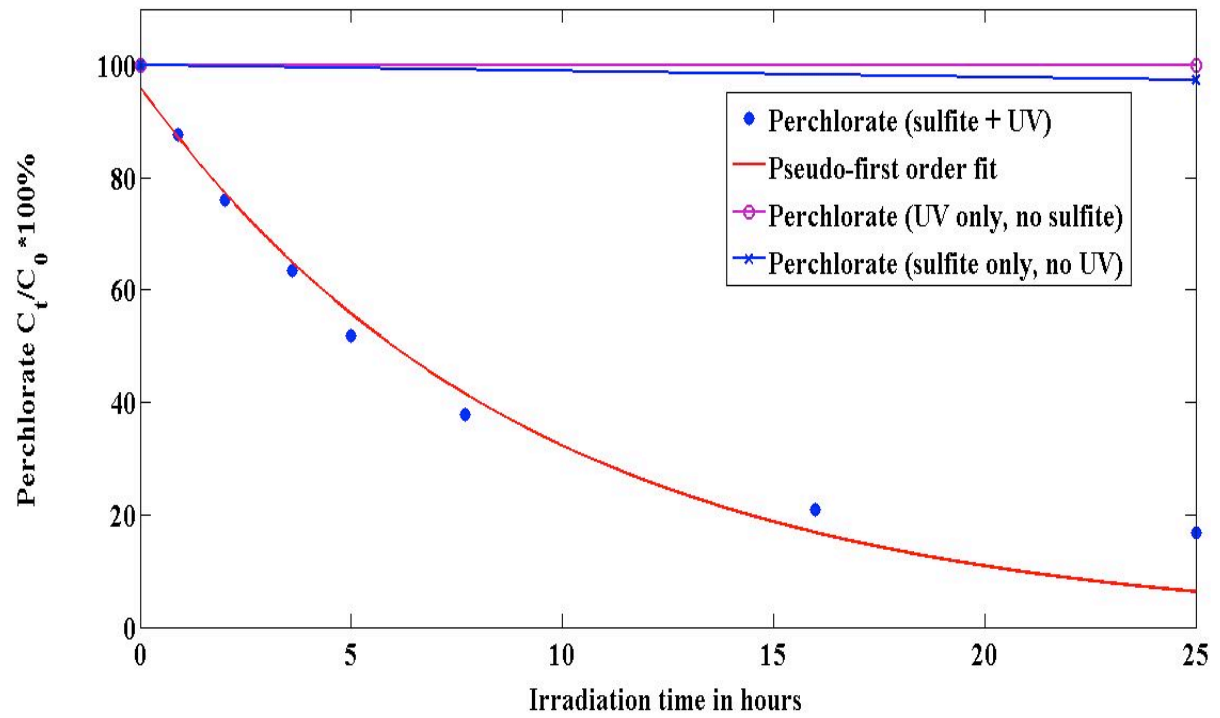

Figure 7. Removal of perchlorate $\left(\mathrm{ClO}_{4}{ }^{-}\right)$with and without irradiation by a UV-L $\operatorname{lamp}\left([\text { perchlorate }]_{\text {initial }}=10 \mathrm{mg} / \mathrm{L},[\right.$ sulfite $]=11 \mathrm{mM}$; UV-L intensity $=9.5 \mathrm{~mW} / \mathrm{cm}^{2}$, $\mathrm{pH}=11)$ 
A general model for production of a free radical and its reaction with a target and a scavenger are described in Equations 23 to 25,

$$
\begin{gathered}
A+h v \rightarrow R \\
R+T \rightarrow \text { products } \\
R+S \rightarrow \text { products }
\end{gathered}
$$

where A represents the reagent; $\mathrm{R}$ represents the free radical; $\mathrm{T}$ represents the target compound; and S represents the scavenger. A material balance on radicals in a batch system is given by:

$$
\frac{d R}{d t}=r_{r x n, i, a v g}-\left(r_{2}+r_{3}\right)
$$

where $\mathrm{t}(\mathrm{hr})$ is the reaction time; $\mathrm{r}_{2}$ is the rate for the reaction described by Equation 24; and $r_{3}$ is the rate of reaction described by Equation 25 . At steady state, the concentration of radicals does not change with time, so

$$
r_{r x n, i, a v g}=r_{2}+r_{3}
$$

Assuming that the rates of reaction with the radical are proportional to the concentration of the radical times the concentration of the target or the scavenger, this becomes Equation 28.

$$
\begin{gathered}
r_{r x n, i, a v g}=k_{2}[T][R]+k_{3}[S][R] \\
{[R]=\frac{r_{r x n, i, a v g}}{k_{2}[T]+k_{3}[S]}}
\end{gathered}
$$


where $\mathrm{k}_{2}$ is the rate constant for Equation 24, in which radicals react with target

compounds, and $\mathrm{k}_{3}$ is the rate constant for reaction which radicals react with scavengers. Combining Equation 21 and 29, concentration of R becomes:

$$
[R]=\frac{-\phi \frac{I_{0}}{L}\left(1-e^{-\varepsilon^{\prime} C L}\right)}{k_{2}[T]+k_{3}[S]}
$$

Therefore, the following equations show the reaction rate $\left(r_{2}\right)$ for radicals reacting with the target compound, which is perchlorate in this research.

$$
\begin{gathered}
r_{2}=k_{2}[T][R] \\
r_{2}=\frac{-\phi \frac{I_{0}}{L}\left(1-e^{-\varepsilon^{\prime} C L}\right) k_{2}}{k_{2}[T]+k_{3}[S]}[T]
\end{gathered}
$$

Equation 32 is the actual reaction rate for perchlorate; however, for a simplified analysis we consider it as a pseudo-first-order decay model. This allows the pseudo-first-order rate constant to be expressed as shown by Equation 33 .

$$
k_{o b s}=\frac{-\phi \frac{I_{0}}{L}\left(1-e^{-\varepsilon^{\prime} C L}\right) k_{2}}{k_{2}[T]+k_{3}[S]}
$$

The pseudo-first-order rate constant for perchlorate removal was estimated to be $0.11 \pm 0.03 \mathrm{hr}^{-1}\left(\mathrm{R}^{2}=0.97\right)$. The results show that perchlorate removal tended to stop after about 16 hours, which was likely caused by there being insufficient sulfite remaining in the solution to effectively reduce perchlorate (Figure 8). 


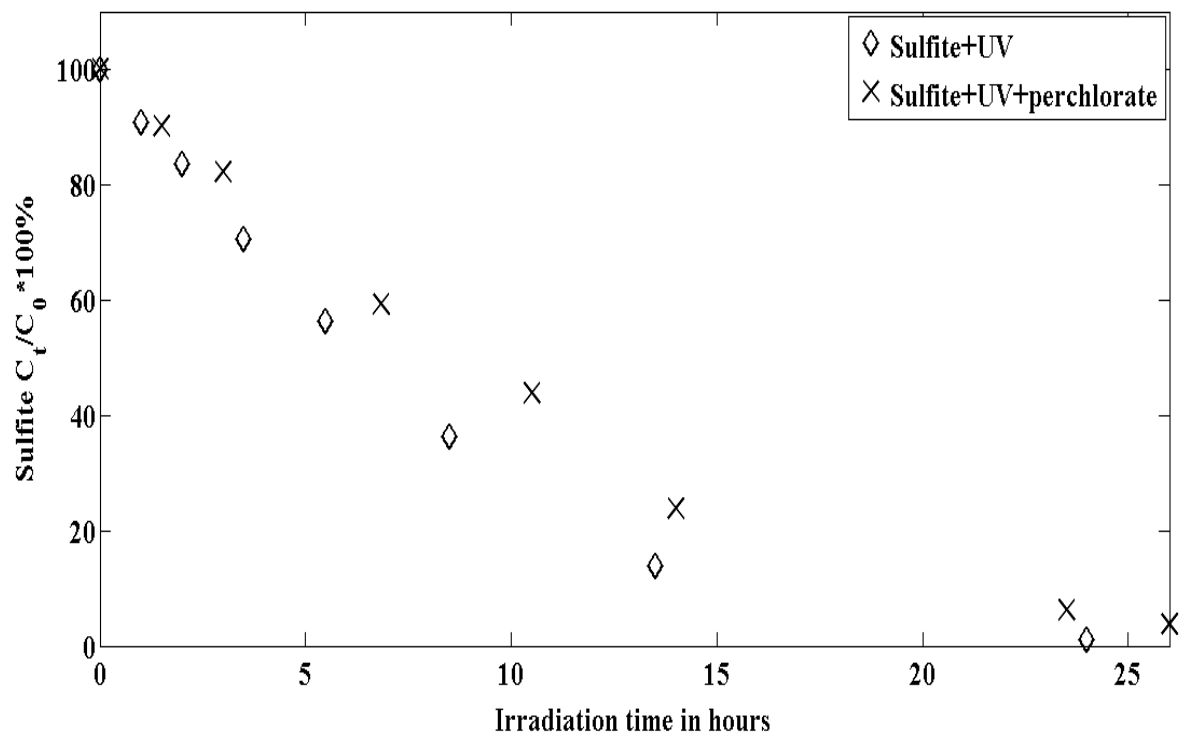

Figure 8. Consumption of sulfite $\left(\mathrm{SO}_{3}{ }^{2-}\right)$ with irradiation by a UV-L lamp with and without perchlorate $\left([\text { sulfite }]_{\text {initial }}=11 \mathrm{mM},[\text { perchlorate }]_{\text {initial }}=10 \mathrm{mg} / \mathrm{L} ; \mathrm{UV}-\mathrm{L}\right.$

$$
\text { intensity } \left.=9.5 \mathrm{~mW} / \mathrm{cm}^{2}, \mathrm{pH}=11\right) \text {. }
$$

In Figure 8, nearly $100 \%$ of initial sulfite was consumed after 25 hours. A faster loss of sulfite was observed in the experiment with only sulfite and irradiation by the UV-L lamp. The quantum yield for sulfite photolysis with UV-L light (Equation 2) was estimated by doing non-linear regression with Equation 14. Values of quantum yield ( $\left.\phi_{\text {sulfite }}\right)$ for sulfite loss are shown in Table 2 . The quantum yields for sulfite/UV-L experiment is a little larger than that of the sulfite/UV-L/perchlorate experiment, which indicates that perchlorate may slow down the reaction of sulfite under irradiation of UVL lamp. 
Table 2. Quantum yield ( $\left.\phi_{\text {sulfite }}\right)$ for sulfite loss during UV-L irradiation with and

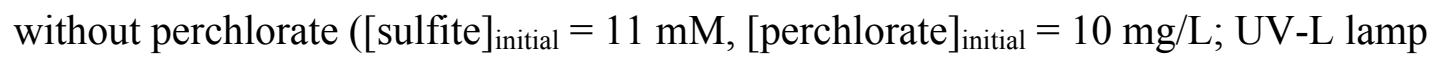

\begin{tabular}{cc}
\multicolumn{2}{c}{ intensity $\left.=9.5 \mathrm{~mW} / \mathrm{cm}^{2}, \mathrm{pH}=11\right)}$. \\
\hline Experimental Conditions & $\phi_{\text {sulfite }}(\mathrm{mol} /$ einstein $)$ \\
\hline Sulfite/UV-L & $0.050 \pm 0.0067$ \\
Sulfite/UV-L/perchlorate & $0.037 \pm 0.0061$ \\
\hline
\end{tabular}

\subsection{Comparison of Sulfite/UV-L and Sulfite/UV-KrCl ARPs}

The influence of the wavelength of UV light on perchlorate reduction was examined by applying the same UV light intensity to a perchlorate solution with sulfite at base conditions. Figure 9a shows that the rate of perchlorate reduction with irradiation by the UV-L (254 nm) lamp was faster than the rate of perchlorate removal with the UV$\mathrm{KrCl}$ lamp. The lines in Figure 9 represent the fit of a pseudo-first-order decay model with coefficients obtained by non-linear regression. The calculated pseudo-first-order rate constant for perchlorate removal was $0.059 \pm 0.01 \mathrm{hr}^{-1}\left(\mathrm{R}^{2}=1.00\right)$ for the 222-nm lamp, which is much lower than the rate constant of $0.11 \pm 0.03 \mathrm{hr}^{-1}\left(\mathrm{R}^{2}=0.97\right)$ for the 254-nm lamp. 
Theoretically, 222-nm UV light should cause more rapid removal of perchlorate than 254-nm light, because sulfite absorbs light more effectively at $222 \mathrm{~nm}$ than at 254 $\mathrm{nm}$, so more sulfite radicals will be generated (37). However, the quantum yield ( $\left.\phi_{\text {sulfite }}\right)$ for loss of sulfite with perchlorate was calculated to be $0.016 \pm 0.0008 \mathrm{~mol} /$ einstein for the 222-nm light, which is less than half the value of the quantum yield $(0.037 \pm 0.0061$ mol/einstein) for the 254-nm light. This indicates that a smaller fraction of photons that are absorbed cause a reaction with the 222-nm light. Therefore, although more photons are being absorbed at $222 \mathrm{~nm}$, fewer radicals are being produced and fewer perchlorate molecules are reduced. Figure 9 shows that after 9 hours irradiation by 222-nm UV light, there is no sulfite remaining in the solution, which will result in suspending perchlorate reduction processes. Degradation of sulfite by photolysis with 254-nm UV light is relatively slow. There was more than $40 \%$ of the initial sulfite remaining in the solution after 10 hours irradiation by $254 \mathrm{~nm}$ UV light (Figure 9b). The remaining sulfite would keep producing sulfite radicals, which would continue to reduce perchlorate until the sulfite was consumed after about 26 hours. 

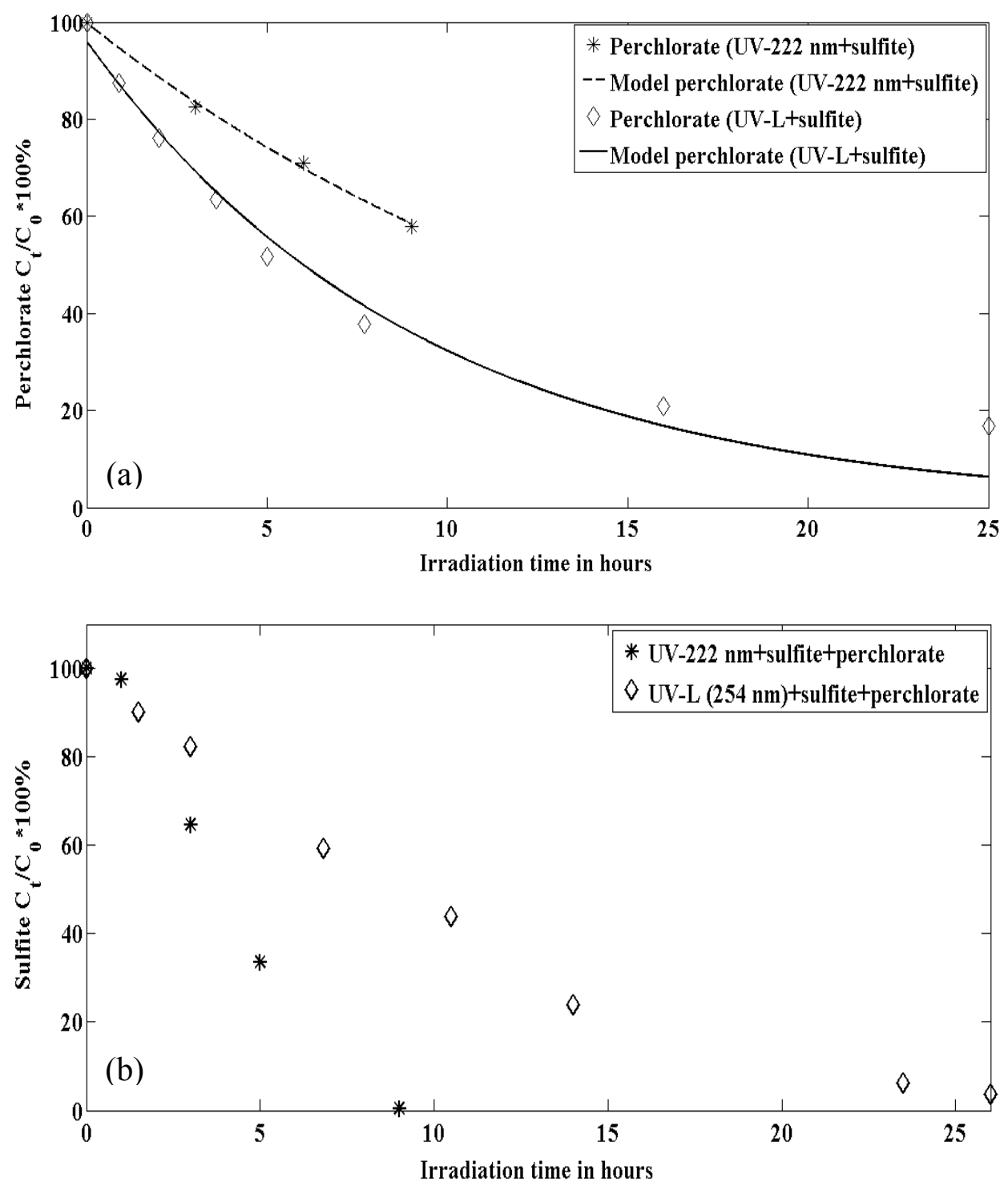

Figure 9. Effect of wavelength of UV light on perchlorate reduction. (a) perchlorate concentration profile and (b) sulfite concentration profile ([perchlorate $]_{\text {initial }}=10 \mathrm{mg} / \mathrm{L}$, $[\text { sulfite }]_{\text {initial }}=11 \mathrm{mM} ; \mathrm{UV}-\mathrm{KrCl}$ and UV-L intensity $\left.=8.5 \mathrm{~mW} / \mathrm{cm}^{2}, \mathrm{pH}=11\right)$. 


\section{IMPACT OF NOM ON PERCHLORATE REDUCTION BY ARP}

\subsection{Effects of NOM on Perchlorate Reduction by Sulfite/UV-KrCI ARP}

\subsubsection{Effect of NOM on Perchlorate Removal}

Experiments were conducted to investigate the effect of NOM concentration on perchlorate removal by the sulfite/UV-KrCl ARP. Portions of a NOM stock solution were added into batch reactors that contained $10 \mathrm{mg} / \mathrm{L}$ perchlorate and $11 \mathrm{mM}$ sulfite at $\mathrm{pH} 11$ in order to obtain concentrations of NOM of 2.5, 5, 10, $30 \mathrm{mg} / \mathrm{L}$ (as carbon). Figure 10 shows the relative concentrations of perchlorate for of each experiment over a time period of 9 hours. Figure 10 shows that the rate of perchlorate reduction decreases as the concentration of NOM increases. The experiment with $30 \mathrm{mg} / \mathrm{L}$ (as carbon) NOM removed only $20 \%$ of perchlorate within 9 hours. At the smallest concentration of NOM used in these experiments $(2.5 \mathrm{mg} / \mathrm{L}$ as carbon $)$, approximately $45 \%$ of perchlorate was removed, which is only 5\% less than that in the experiment without NOM.

Table 3 shows the rate constants of the pseudo-first-order model that were obtained by non-linear regression. Observed first-order rate constants are decreasing when the concentration of NOM is increasing. This result indicates that NOM inhibits perchlorate reduction with sulfite and the UV-KrCl lamp, even at low concentration. 


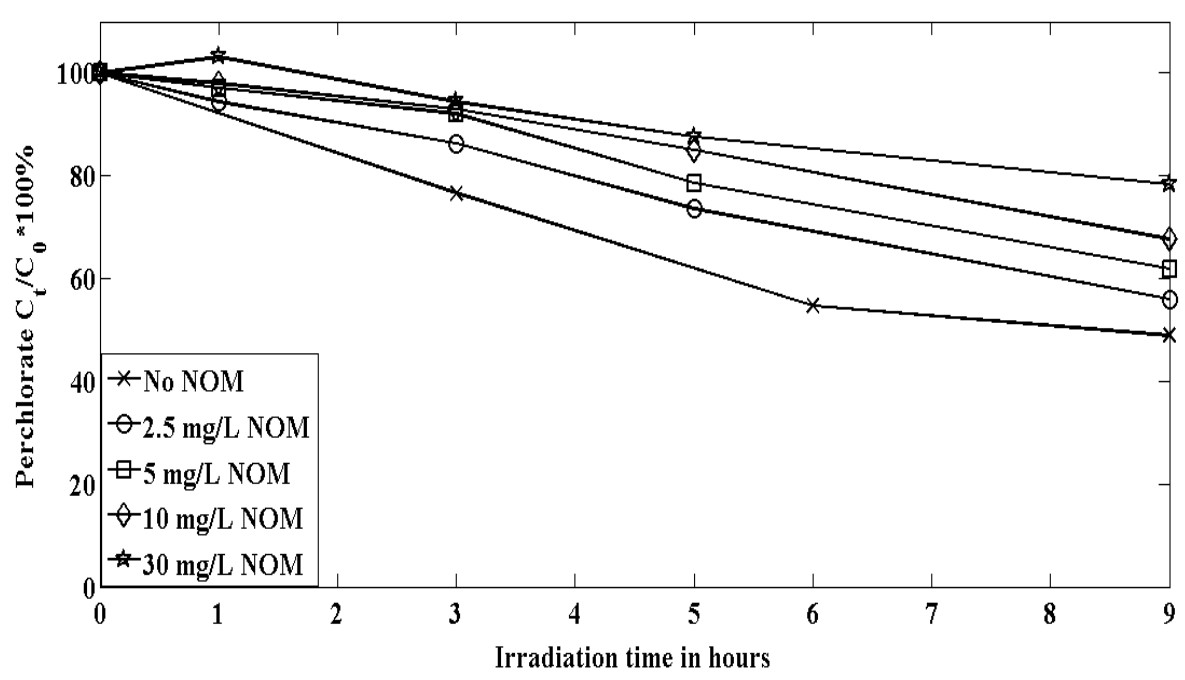

Figure 10. Effect of NOM on removal of perchlorate $\left(\mathrm{ClO}_{4}^{-}\right)$with sulfite and

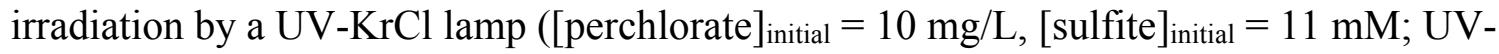
$\mathrm{KrCl}$ lamp intensity $\left.=13 \mathrm{~mW} / \mathrm{cm}^{2}, \mathrm{pH}=11\right)$.

Table 3. Pseudo-first-order rate constant $\left(\mathrm{k}_{\mathrm{obs}}\right)$ and $\mathrm{R}^{2}$ values for perchlorate removal at different concentrations of $\operatorname{NOM}\left([\text { perchlorate }]_{\text {initial }}=10 \mathrm{mg} / \mathrm{L},\left[\right.\right.$ sulfite $_{\text {initial }}=$ $11 \mathrm{mM}$; UV-KrCl lamp intensity $\left.=13 \mathrm{~mW} / \mathrm{cm}^{2}, \mathrm{pH}=11\right)$.

\begin{tabular}{ccc}
\hline NOM Concentration as C $(\mathrm{mg} / \mathrm{L})$ & $\mathrm{k}_{\mathrm{obs}}\left(\mathrm{hr}^{-1}\right)$ & $\mathrm{R}^{2}$ \\
\hline 0 & $0.087 \pm 0.039$ & 0.98 \\
2.5 & $0.063 \pm 0.011$ & 0.99 \\
5 & $0.053 \pm 0.019$ & 0.97 \\
10 & $0.042 \pm 0.015$ & 0.97 \\
30 & $0.030 \pm 0.013$ & 0.95 \\
\hline
\end{tabular}


The ability of NOM to inhibit removal of perchlorate by ARP may be due to it competing with sulfite for the absorption of UV light, which is used to produce reactive radicals that reduce perchlorate. It has been reported that NOM absorbs UV light from $220 \mathrm{~nm}$ to $280 \mathrm{~nm}$ and measurements of this absorbance in this range could be used for characterization of NOM (7). Additionally, NOM could photolyze to smaller molecules under irradiation by UV light (17). Studies $(15,17-18)$ suggested that AOPs can effectively remove NOM from solution and that the hydroxyl radicals produced by AOPs could enhance the removal process by reacting with $\operatorname{NOM}(15,34)$. Therefore, there is a possibility that some of the species produced from sulfite (sulfite radical anion and hydrated electron) were able to react with NOM.

The following sections study the loss of NOM and sulfite in during UV irradiation and support part of the hypothesis that NOM scavenges radicals produced by sulfite photolysis.

\subsubsection{Loss of NOM-absorbance}

Experiments were conducted to investigate the loss of NOM as measured by UV absorbance (NOM-absorbance) at $270 \mathrm{~nm}$. Figure 11 shows results of an experiment where more than $50 \%$ of initial NOM-absorbance was removed within 7 hours of irradiation with $222 \mathrm{~nm}$ light at $\mathrm{pH}$ 11. But when sulfite was added into the reactor and irradiated, over $95 \%$ of the initial NOM-absorbance was removed within 5 hours. These results demonstrate that NOM can absorb UV light at $222 \mathrm{~nm}$ and photolyze, but that the process is more rapid when sulfite is present and producing reactive species. The impact of sulfite suggests that it or reactive species produced by its photolysis reacted with 
NOM. Figure 11 also shows that perchlorate has no effect on the loss of NOMabsorbance with sulfite and UV-KrCl irradiation at $\mathrm{pH} 11$. The solid lines of sulfite/UV/NOM and sulfite/UV/perchlorate/NOM experiments almost coincide with each other. With perchlorate in the system, there was still more than $95 \%$ of the initial NOM-absorbance removed within 5 hours of irradiation with the UV-KrCl lamp.

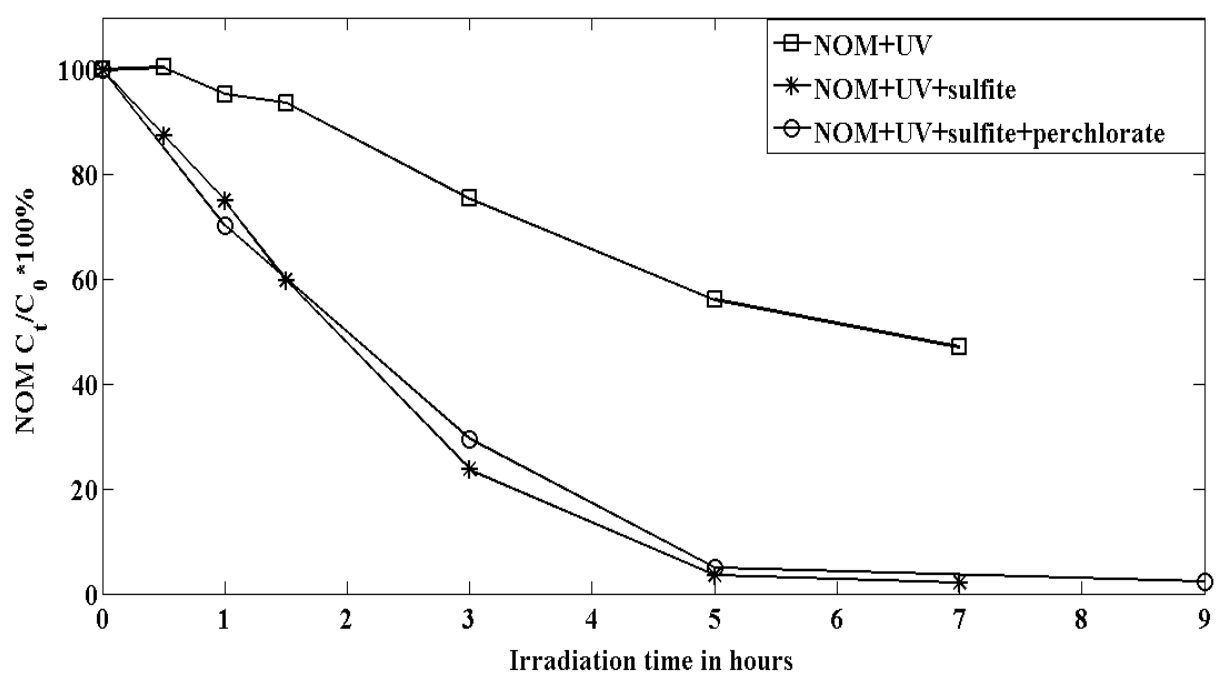

Figure 11. Loss of NOM-absorbance during irradiation by a UV-KrCl lamp under different conditions $\left([\mathrm{NOM}]=50 \mathrm{mg} / \mathrm{L}\right.$ as carbon, $[\text { perchlorate }]_{\text {initial }}=10 \mathrm{mg} / \mathrm{L}$, $\left[\right.$ sulfite $_{\text {initial }}=11 \mathrm{mM} ; \mathrm{UV}-\mathrm{KrCl}$ lamp intensity $\left.=13 \mathrm{~mW} / \mathrm{cm}^{2}, \mathrm{pH}=11\right)$.

\subsubsection{Loss of Sulfite}

Figure 12 shows concentrations of sulfite over time during 222-nm irradiation under different conditions. The curve for the solution without perchlorate is very close to the curve for the solution with perchlorate, which indicates that the presence of 
perchlorate in the system has little effect on sulfite photolysis with the UV-KrCl lamp. All of the initial sulfite was consumed in both experiments within 9 hours. However, when NOM was added, the rate of loss of sulfite was decreased to a large extent. Only $60 \%$ of the initial sulfite was removed within 7 hours. This result further demonstrates that NOM inhibits the reaction of sulfite with UV light, possibly due to NOM competing with sulfite for UV light.

Table 4 shows the quantum yield for sulfite for each experiment. These quantum yields were calculated by doing non-linear regression with Equation 20 and 21 using the Matlab function nlinfit. The model values were obtained by solving the differential equations numerically with the Matlab function ode45 (see Appendix C.3). For experiment without NOM, Equation 21 was applied. But for experiment with NOM, Equation 20 was used, because it considers the light absorption by all dissolved compounds that absorb light, i.e. sulfite and NOM.

$$
\begin{gathered}
\frac{d C_{i}}{d t}=\frac{\phi \varepsilon_{i}^{\prime} C_{i} I_{0}}{\alpha^{\prime}{ }_{\text {all }} L}\left(1-e^{-\alpha_{\text {all }}^{\prime} L}\right) \\
\frac{d C}{d t}=-\phi \frac{I_{0}}{L}\left(1-e^{-\varepsilon^{\prime} C L}\right)
\end{gathered}
$$

Table 4 shows that the estimated quantum yields in the presence of perchlorate are a little lower (10-25\%) than those in its absence. The quantum yields for sulfite removal in the presence of NOM are about 30-40\% lower than in its absence. 


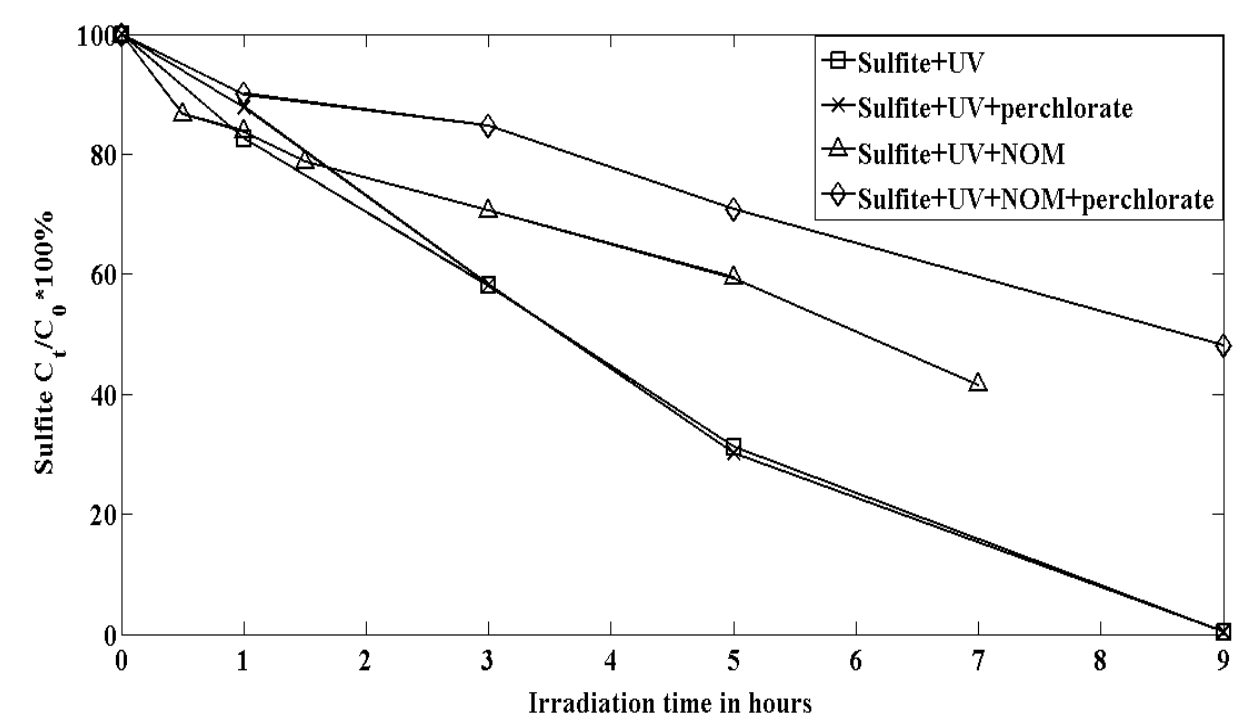

Figure 12. Loss of sulfite by irradiation with a UV-KrCl lamp under different conditions $\left([\text { perchlorate }]_{\text {initial }}=10 \mathrm{mg} / \mathrm{L},[\text { sulfite }]_{\text {initial }}=11 \mathrm{mM},[\mathrm{NOM}]=50 \mathrm{mg} / \mathrm{L}\right.$ as carbon; $\mathrm{UV}-\mathrm{KrCl}$ lamp intensity $\left.=13 \mathrm{~mW} / \mathrm{cm}^{2}, \mathrm{pH}=11\right)$.

Table 4. Quantum yield ( $\phi_{\text {sulfite }}$ ) for loss of sulfite by irradiation with a UV-KrCl lamp under different conditions $\left([\text { perchlorate }]_{\text {initial }}=10 \mathrm{mg} / \mathrm{L},[\text { sulfite }]_{\text {initial }}=11 \mathrm{mM}\right.$, $[\mathrm{NOM}]=50 \mathrm{mg} / \mathrm{L}$ as carbon; UV- $\mathrm{KrCl}$ lamp intensity $\left.=13 \mathrm{~mW} / \mathrm{cm}^{2}, \mathrm{pH}=11\right)$.

\begin{tabular}{cc}
\hline Experimental Conditions & $\phi_{\text {sulfite }}(\mathrm{mol} /$ einstein $)$ \\
\hline Sulfite/UV & $0.018 \pm 0.0018$ \\
Sulfite/UV/perchlorate & $0.016 \pm 0.0008$ \\
Sulfite/UV/NOM & $0.013 \pm 0.0031$ \\
Sulfite/UV/perchlorate/NOM & $0.010 \pm 0.0038$ \\
\hline
\end{tabular}




\subsection{Effects of NOM on Perchlorate Reduction by Sulfite/UV-L ARP}

\subsubsection{Effect of NOM on Perchlorate Removal}

The influence of NOM on perchlorate removal was examined by adding different levels of NOM in experiments conducted with the UV-L lamp irradiating solutions of 10 $\mathrm{mg} / \mathrm{L}$ perchlorate and $11 \mathrm{mM}$ sulfite. All experiments were conducted under same conditions except for the concentration of NOM. Figure 13 shows that the rate of perchlorate reduction decreases with increasing concentration of NOM. There was no perchlorate removal within 14 hours in the experiment with $50 \mathrm{mg} / \mathrm{L}$ (as carbon) NOM. After 25 hours irradiation, less than $10 \%$ of the initial perchlorate had been removed. For the smallest concentration of NOM that was applied in the experiment $(2.5 \mathrm{mg} / \mathrm{L}$ as carbon), only $55 \%$ of perchlorate was removed, which is approximately $25 \%$ less than that in the experiment without NOM.

Pseudo-first-order rate constants for perchlorate reduction with NOM were estimated by doing non-linear regressions and the results are listed in Table 5. Again, $\mathrm{k}_{\mathrm{obs}}$ decreases as the concentration of NOM increases. The observed pseudo-first-order rate constant for the experiment with $\mathrm{NOM}$ concentration at $2.5 \mathrm{mg} / \mathrm{L}$ is less than half of that for the experiment without NOM. This result indicates that NOM significantly inhibits perchlorate reduction with the UV-L lamp, even at low concentrations. 


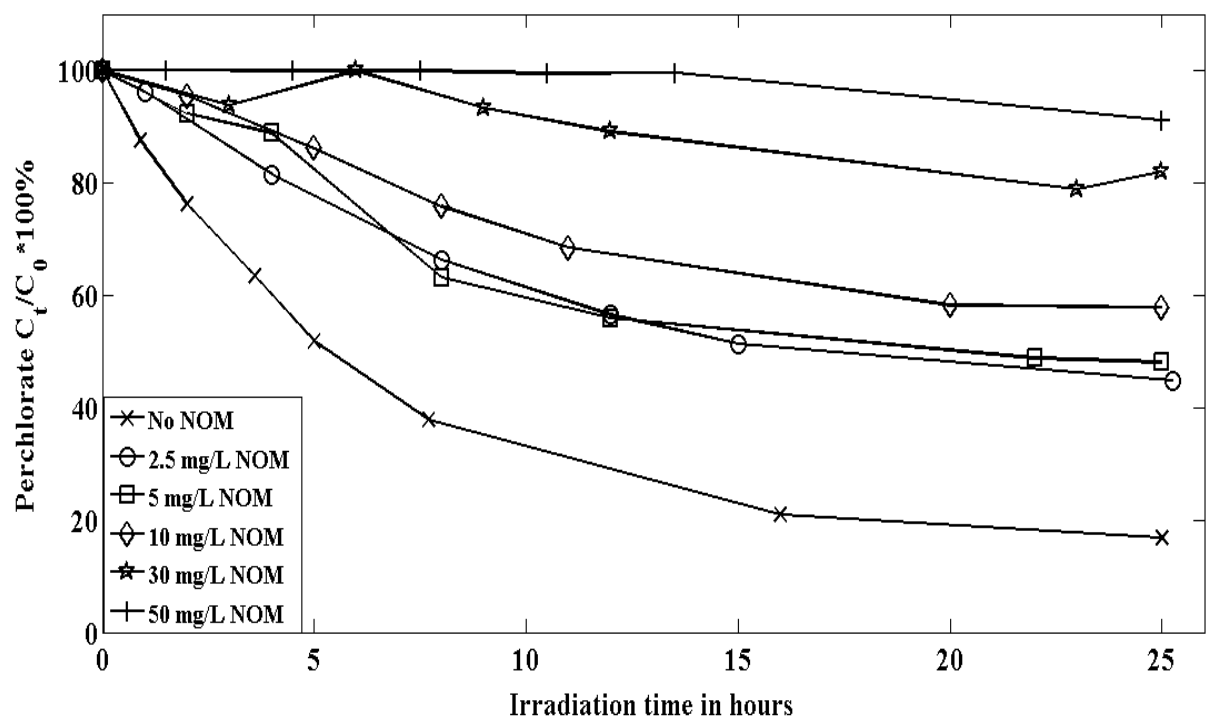

Figure 13. Effect of NOM on removal of perchlorate $\left(\mathrm{ClO}_{4}{ }^{-}\right)$with the sulfite/UV-L/ ARP $\left([\text { perchlorate }]_{\text {initial }}=10 \mathrm{mg} / \mathrm{L},[\right.$ sulfite $]=11 \mathrm{mM} ; \mathrm{UV}-\mathrm{L}$ intensity $=$ $\left.9.5 \mathrm{~mW} / \mathrm{cm}^{2}, \mathrm{pH}=11\right)$. 
Table 5. Pseudo-first-order rate constant $\left(\mathrm{k}_{\mathrm{obs}}\right)$ and $\mathrm{R}^{2}$ values for perchlorate removal in the presence of $\mathrm{NOM}\left([\text { perchlorate }]_{\text {initial }}=10 \mathrm{mg} / \mathrm{L},[\text { sulfite }]_{\text {initial }}=11 \mathrm{mM}\right.$; UV-L lamp intensity $\left.=9.5 \mathrm{~mW} / \mathrm{cm}^{2}, \mathrm{pH}=11\right)$.

\begin{tabular}{ccc}
\hline NOM Concentration as C $(\mathrm{mg} / \mathrm{L})$ & $\mathrm{k}_{\text {obs }}\left(\mathrm{hr}^{-1}\right)$ & $\mathrm{R}^{2}$ \\
\hline 0 & $0.11 \pm 0.03$ & 0.97 \\
2.5 & $0.039 \pm 0.011$ & 0.95 \\
5 & $0.034 \pm 0.014$ & 0.91 \\
10 & $0.025 \pm 0.0074$ & 0.95 \\
30 & $0.0090 \pm 0.0040$ & 0.87 \\
50 & $0.0033 \pm 0.0024$ & 0.73 \\
\hline
\end{tabular}

\subsubsection{Loss of NOM-absorbance}

The loss of NOM-absorbance during irradiation with the UV-L lamp was measured under different conditions. Figure 14 shows the results of experiments at $\mathrm{pH}$ 11 in solutions with NOM-only, with sulfite/NOM, and with sulfite/perchlorate/NOM. UV-L irradiation of the solution with only NOM removed only $20 \%$ of the initial NOMabsorbance within 12.5 hours. But when sulfite was added to the system, almost $100 \%$ of the initial NOM-absorbance was removed within 12.5 hours. Sulfite significantly enhances the NOM reaction with UV-L lamp at $\mathrm{pH} 11$. This result also indicates that radicals produced by photolysis of sulfite may react with NOM. In contrast with the results with UV-KrCl, Figure 14 shows that to some extent, perchlorate inhibited the loss 
of NOM-absorbance in the presence of sulfite with UV-L. With perchlorate in the system, only $70 \%$ of the initial NOM-absorbance was removed within 13.5 hours under irradiation with the UV-L lamp, which is $30 \%$ less than that in the sulfite/NOM experiments. However, NOM-absorbance was nearly completely removed in the sulfite/perchlorate/NOM experiment after irradiation with the UV-L lamp for 25 hours. The reasons for different behavior with the two lamps (UV-KrCl and $\mathrm{UV}-\mathrm{L}$ ) could be the higher light intensity $\left(13 \mathrm{~mW} / \mathrm{cm}^{2}\right.$ compare to $\left.9.5 \mathrm{~mW} / \mathrm{cm}^{2}\right)$ that was applied to the reactor with the UV-KrCl lamp or it could be due to the higher absorbance of NOM at $222 \mathrm{~nm}$ (Figure 15). Both would lead to higher rates of absorption of UV light by NOM. The quantum yields $\left(\phi_{\mathrm{NOM}}\right)$ calculated for loss of NOM-absorbance by irradiation with a $\mathrm{UV}-\mathrm{KrCl}$ lamp is $0.0041 \pm 0.0007 \mathrm{~mol} /$ einstein, which is more than three times of that for NOM irradiation with a UV-L lamp $(0.0012 \pm 0.0002 \mathrm{~mol} /$ einstein $)$. This indicates that not only was more UV light absorbed at $222 \mathrm{~nm}$, it was more effective in destroying NOM-absorbance. Figure 15 shows the absorbance spectra of NOM at different concentrations (10 mg/L to $60 \mathrm{mg} / \mathrm{L}$ as carbon). For each concentration of NOM, the absorbance decreases with increasing wavelength from $210 \mathrm{~nm}$ to $300 \mathrm{~nm}$. Higher absorbance of NOM at $222 \mathrm{~nm}$ could result in faster degradation of NOM. Therefore, $\mathrm{NOM}$ in the presence of sulfite and irradiated by the UV-KrCl lamp would be removed very fast, even with perchlorate in the solution. However, with the UV-L lamp that generates light at $254 \mathrm{~nm}$, the rate of loss of NOM would be smaller because the lower absorbance at $254 \mathrm{~nm}$ would mean that NOM had a lower rate of photolysis. 


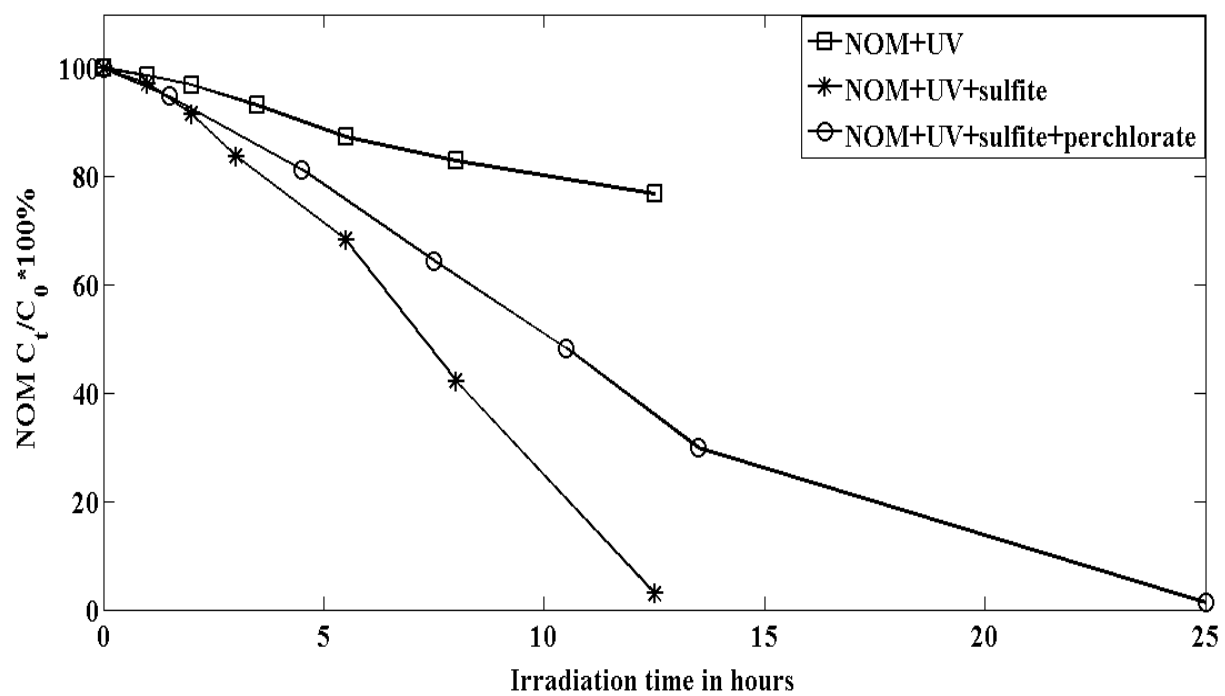

Figure 14. Loss of NOM with UV-L lamp under different conditions ([NOM] $=$

$50 \mathrm{mg} / \mathrm{L}$ as carbon, $[\text { perchlorate }]_{\text {initial }}=10 \mathrm{mg} / \mathrm{L},[\text { sulfite }]_{\text {initial }}=11 \mathrm{mM}$; UV-L intensity

$$
\left.=9.5 \mathrm{~mW} / \mathrm{cm}^{2}, \mathrm{pH}=11\right) \text {. }
$$




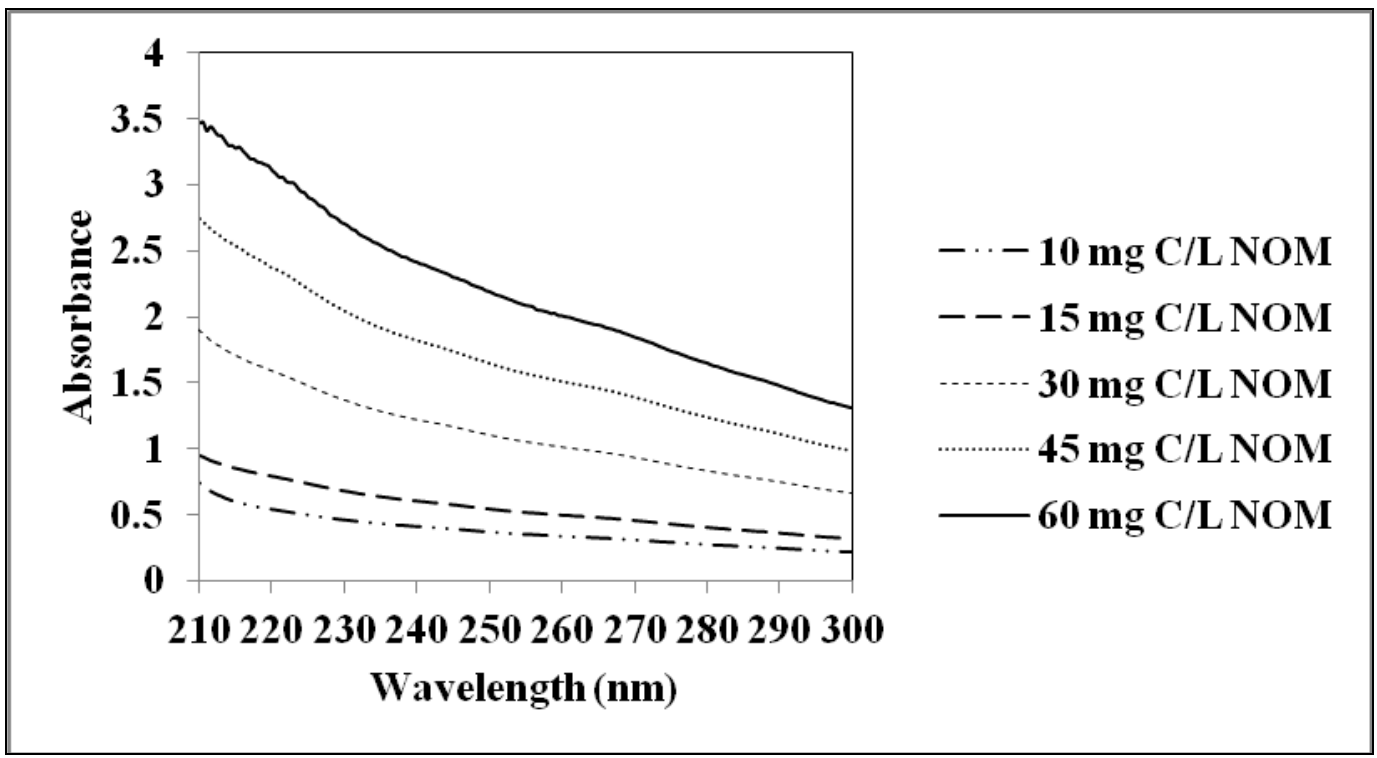

Figure 15. Absorbance spectra for different concentrations of NOM from 210 $\mathrm{nm}$ to $300 \mathrm{~nm}(\mathrm{pH}=11)$.

\subsubsection{Loss of Sulfite}

Figure 16 shows sulfite concentrations over time under different conditions. The loss rate of sulfite during irradiation without perchlorate is a little larger than that with perchlorate, which indicates that perchlorate lowers the rate of sulfite photolysis to some extent. But, eventually, $100 \%$ of the sulfite was consumed in both experiments with and without perchlorate within 26 hours. Nevertheless, the presence of NOM (50 mg/L as C) resulted in about $15 \%$ loss of sulfite over the first 13-14 hours. NOM is competing for UV light with sulfite. In addition, some of intermediates produced by degradation of NOM in first 14 hours may absorb UV light at the wavelength used to measure sulfite, which would interfere with the measurement of sulfite concentration. Overall, these 
results demonstrate that NOM strongly inhibits perchlorate removal by the sulfite/UV-L ARP.

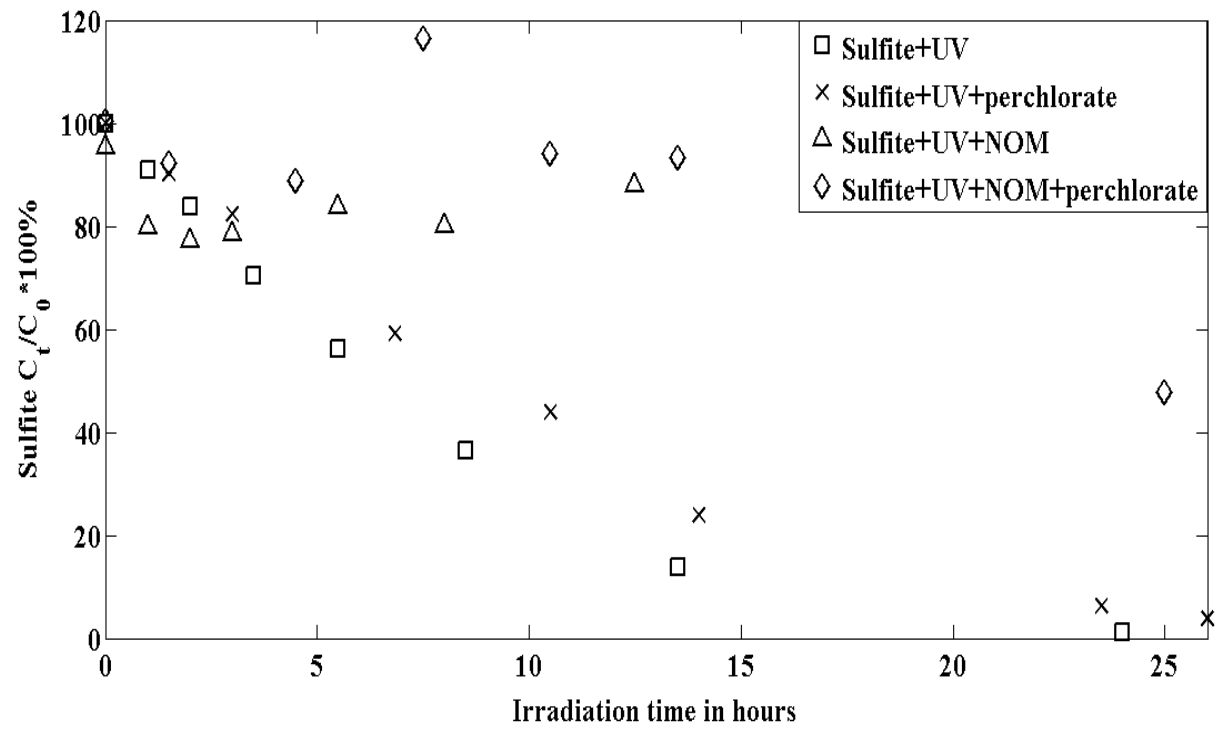

Figure 16. Loss of sulfite with UV-L lamp under different conditions

$\left([\text { perchlorate }]_{\text {initial }}=10 \mathrm{mg} / \mathrm{L},[\text { sulfite }]_{\text {initial }}=11 \mathrm{mM},[\mathrm{NOM}]=50 \mathrm{mg} / \mathrm{L}\right.$ as carbon; UV-L lamp intensity $\left.=9.5 \mathrm{~mW} / \mathrm{cm}^{2}, \mathrm{pH}=11\right)$. 


\section{CONCLUSIONS}

There are two variables whose effect on destruction of perchlorate by the ARP using sulfite and activated by ultraviolet light: the wavelength of UV light and concentration of NOM. Perchlorate reduction occurred faster with irradiation by the UV$\mathrm{L}(254 \mathrm{~nm})$ lamp than that with the UV-KrCl (222 nm) lamp. Increasing the concentration of NOM resulted in decreasing the rate of perchlorate reduction.

Perchlorate degradation kinetics were identified by doing non-linear regression using Matlab and the coefficients obtained were used to evaluate the effects of NOM and wavelength of light on perchlorate removal.

Without NOM, more than $50 \%$ of perchlorate was removed after 9 hours by the sulfite/UV-KrCl ARP at base conditions, and the recovery of chlorine was about $76 \%$. On the other hand, more than $80 \%$ of perchlorate was removed after 25 hours with sulfite and UV-L irradiation. Depletion of sulfite is the main reason that perchlorate reduction slowed and stopped. The calculated pseudo-first-order rate constant for perchlorate removal was $0.059 \pm 0.01 \mathrm{hr}^{-1}\left(\mathrm{R}^{2}=1.00\right)$ for the 222-nm lamp, which is much lower than the rate constant of $0.11 \pm 0.03 \mathrm{hr}^{-1}\left(\mathrm{R}^{2}=0.97\right)$ for the 254-nm lamp. This is because although more photons are absorbed with 222-nm light, they have a lower effectiveness in producing a reaction that forms radicals.

With NOM, approximately $45 \%$ of perchlorate was removed after 9 hours by the sulfite/UV-KrCl ARP at base conditions when NOM concentration is $2.5 \mathrm{mg} / \mathrm{L}$ as carbon. When NOM was present at $30 \mathrm{mg} / \mathrm{L}$ (as carbon), only $20 \%$ of perchlorate was 
removed after 9 hours. For experiments with the UV-L lamp, only 55\% of perchlorate was removed in the presence of $2.5 \mathrm{mg} / \mathrm{L}$ (as carbon) NOM after 25 hours, which is $25 \%$ less than that in the experiment without NOM. Less than $10 \%$ of perchlorate was removed in the experiment with $50 \mathrm{mg} / \mathrm{L}$ (as carbon) NOM. The rate of perchlorate reduction decreased with increasing concentrations of NOM. Additionally, results from UV/NOM and sulfite/UV/NOM experiments indicate that adding sulfite enhanced the removal of NOM-absorbance. Adding NOM to the sulfite/UV system decreased the rate of loss of sulfite to a large extent. The ability of NOM to inhibit removal of perchlorate by ARP is due to it competing for UV light with sulfite and to it scavenging radicals produced by sulfite photolysis.

Overall, this study has provided information about influence of NOM and UV wavelength on perchlorate removal by ARP processes. NOM strongly inhibits perchlorate removal by either the sulfite/UV-KrCl or the sulfite/UV-L ARP because NOM is a competitor with sulfite for UV light and a scavenger for produced radicals. Even though the absorbance of sulfite is much higher at UV wavelength of $222 \mathrm{~nm}$ than that at $254 \mathrm{~nm}$, the results indicate that more perchlorate was removed with the UV-L lamp than with the UV-KrCl lamp. This is because the effectiveness of photons in producing radicals is higher with UV-L lamp than that with UV-KrCl lamp, even though the absorption of photons is lower. The results of this study will provide information to support development of the processes as a practical water treatment method. 


\section{REFERENCES}

(1) U.S. Environmental Protection Agency. Emerging contaminant: Perchlorate; EPA/505-F-10-002; U.S. Environmental Protection Agency: Cincinnati, OH, 2010.

(2) U.S. Environmental Protection Agency. Perchlorate (CLU-IN.ORG). Accessed Jun $15,2012$.

http://www.clu-in.org/contaminantfocus/default.focus/sec/perchlorate/cat/Overview/

(3) Srinivasan, A.; Viraraghavan, T. Perchlorate: Health effects and technologies for its removal from water resources. Int. J. Environ. Res. Public Health. 2009, 6, 14181442.

(4) Rajagopalan, S.; Anderson, T.; Cox, S.; Harvey, G.; Cheng, Q-Q.; Jackson, W. A. Perchlorate in wet deposition across North America. Environ. Sci. Technol. 2009, 43, 616-622.

(5) The Interstate Technology \& Regulatory Council. Perchlorate: Overview of issues, status, and remedial options; The Interstate Technology \& Regulatory CouncilPerchlorate Team: Washington, DC, 2005.

(6) Barrett, S. E.; Krasner, S. W.; Amy, G. L. Natural organic matter and disinfection by-products: Characterization and control in drinking water: An overview. In Natural Organic Matter and Disinfection By-products; Barrett, S. E., Krasner, S. W., Amy, G. L., Eds.; American Chemical Society: Washington, DC, 2000; pp 2-14.

(7) Matilainen, A.; Gjessing, E. T.; Lahtinen, T.; Hed, L.; Bhatnagar, A.; Sillanpaa, M. An overview of the methods used in the characterization of natural organic matter (NOM) in relation to drinking water treatment. Chemosphere. 2011, 83, 1431-1442.

(8) Mayer, K. P. Transmittal of perchlorate maps and table, updated April, 2003; Health \& Environmental Research Online ID 051511; U.S. Environmental Protection Agency: San Francisco, CA, 2003.

(9) Her, N.; Kim, J.; Yoon, Y. Perchlorate in dairy milk and milk-based powdered infant formula in South Korea. Chemosphere. 2010, 81, 732-737.

(10)Picture of Perchlorate Anion. Accessed Jun 15, 2012. http://www.chemistry.wustl.edu/ edudev/LabTutorials/PeriodicProperties/Ions/ions. html 
(11) James J. J. C. Toxicology of perchlorate. In Perchlorate in the Environment; Urbansky, E. T., Ed.; Kluwer Academic/Plenum Publishers: New York, NY, 2000; pp 15-29.

(12)U.S. Environmental Protection Agency. Drinking water: Regulatory determination on perchlorate. Federal Register-Proposed Rules. 2011, 76, 7762-7767.

(13)U.S. Environmental Protection Agency. EPA sets reference dose for perchlorate, 2005. Accessed Jun 15, 2012. http://yosemite.epa.gov/opa/admpress.nsf/0/c1a57d2077c4bfda85256fac005b8b32? OpenDocument

(14)U.S. Environmental Protection Agency. Interim drinking water health advisory for perchlorate; EPA/822-R-08-025; U.S. Environmental Protection Agency: Washington, DC, 2008.

(15)Matilainen, A.; Sillanpaa, M. Removal of natural organic matter from drinking water by advanced oxidation processes. Chemosphere. 2010, 80, 351-365.

(16)Minear, R. A.; Amy, G. L. Water treatment and natural organic matter: History and overview. In Water Disinfection and Natural Organic Matter; Minear, R. A., Amy, G. L., Eds.; American Chemical Society: Washington, DC, 1996; pp 1-9.

(17)Goslan, E. H.; Gurses, F.; Banks, J.; Parsons, S. A. An investigation into reservoir NOM reduction by UV photolysis and advanced oxidation processes. Chemosphere. 2006, 65, 1113-1119.

(18)Buchanan, W.; Roddick, F.; Porter, N.; Drikas, M. Enhanced biodegradability of UV and VUV pre-treated natural organic matter. Water Sci. Technol. Water Supply. 2004, 4, 103-111.

(19)U.S. Environmental Protection Agency. Method 314.0-Determination of perchlorate in drinking water using ion chromatography, Revision 1.0; EPA/815/B-99/003; U.S. Environmental Protection Agency: Cincinnati, OH, 1999.

(20)U.S. Environmental Protection Agency. Method 332.0-Determination of perchlorate in drinking water by ion chromatography with suppressed conductivity and electrospray ionization mass spectrometry, Revision 1.0; EPA/600/R-05/049; U.S. Environmental Protection Agency: Cincinnati, OH, 2005.

(21)Thorne, P. G. Field screening method for perchlorate in water and soil; ERDC/CRREL TR-04-8; U.S. Army Corps of Engineers, 2004. 
(22)U.S. Environmental Protection Agency. Method 6850-Perchlorate in water, soils and solid wastes using high performance liquid chromatography/electrospray ionization/mass spectrometry (HPLC/ESI/MS or HPLC/ESI/MS/MS), Revision 0; U.S. Environmental Protection Agency: Cincinnati, OH, 2007.

(23) National Aeronautics and Space Administration (NASA) \& Jet Propulsion Laboratory. Final: Perchlorate $\left(\mathrm{ClO}_{4}^{-}\right)$treatment technologies literature review operable unit 1 expanded treatability study; EPA/CA9800013030; NASA \& Jet Propulsion Laboratory: Pasadena, CA, 2006.

(24)Sahu, A. K.; Conneely, T.; Nusslein, K. R.; Ergas, S. J. Biological perchlorate reduction in packed bed reactors using elemental sulfur. Environ. Sci. Technol. 2009, 43, 4466-4471.

(25)Achenbach, L. A.; Bender, K. S.; Sun, Y.; Coates, J. D. The biochemistry and genetics of microbial perchlorate reduction. In Perchlorate: Environmental Occurrence, Interactions, and Treatment; Gu, B., Coates, J. D., Eds.; Springer Science+Business Media, Inc.: New York, NY, 2006; pp 297-310.

(26)Brown, G. M.; Gu, B. Recent advances in ion exchange for perchlorate treatment, recovery and destruction. In Perchlorate: Environmental Occurrence, Interactions, and Treatment; Gu, B., Coates, J. D., Eds.; Springer Science+Business Media, Inc.: New York, NY, 2006; pp 209-252.

(27)Parette, R.; Cannon, F. S. Perchlorate removal by modified activated carbon. In Perchlorate: Environmental Occurrence, Interactions, and Treatment; Gu, B., Coates, J. D., Eds.; Springer Science+Business Media, Inc.: New York, NY, 2006; pp 343-372.

(28)Gu, B.; Bonnesen, P. V.; Sloop, F. V.; Brown, G. M. Titanium catalyzed perchlorate reduction and applications. In Perchlorate: Environmental Occurrence, Interactions, and Treatment; Gu, B., Coates, J. D., Eds.; Springer Science+Business Media, Inc.: New York, NY, 2006; pp 373-387.

(29)Oh, S-Y.; Chiu, P. C.; Kim, B. J.; Cha, D. K. Enhanced reduction of perchlorate by elemental iron at elevated temperatures. J. Hazard. Mater. 2006, B129, 304-307.

(30) Im, J-K.; Son, H-S.; Zoh, K-D. Perchlorate removal in $\mathrm{Fe}^{0} / \mathrm{H}_{2} \mathrm{O}$ systems: Impacts of oxygen availability and UV radiation. J. Hazard. Mater. 2011, 192, 457-464.

(31)Zhang, Y.; Hurley, K. D.; Shapley, J. R. Heterogeneous catalytic reduction of perchlorate in water with $\mathrm{Re}-\mathrm{Pd} / \mathrm{C}$ catalysts derived from an oxorhenium (V) molecular precursor. Inorg. Chem. 2011, 50, 1534-1543. 
(32)Hurley, K. D.; Zhang, Y.; Shapley, J. R. Ligand-enhanced reduction of perchlorate in water with heterogeneous Re-Pd/C catalysts. J. Am. Chem. Soc. 2009, 131, 14172-14173.

(33)Hurley, K. D.; Shapley, J. R. Efficient heterogeneous catalytic reduction of perchlorate in water. Environ. Sci. Technol. 2007, 41, 2044-2049.

(34)Crittenden, J. C.; Trussell, R. R.; Hand, D. W.; Howe, K. J.; Tchobanoglous, G. Water treatment principles and design, $2^{\text {nd }}$ Edition; John Wiley and Sons, Inc.: Hoboken, NJ, 2005.

(35)Metcalf \& Eddy Inc.; Tchobanoglous, G.; Burton, F. L.; Stensel, H. D. Wastewater engineering: treatment and reuse, $4^{\text {th }}$ Edition; McGraw-Hill: New York, NY, 2003.

(36)Pemberton, R. S.; Depew, M. C.; Heitner, C.; Wan, J. K. S. Some mechanistic insights into a model bleaching process for quinones by bisulfite and dithionite: An ESR-CIDEP study. J. Wood Chem. Technol. 1995, 15, 65-83.

(37)McFeeters, R. F.; Barish, A. O. Sulfite analysis of fruits and vegetables by highperformance liquid chromatography (HPLC) with ultraviolet spectrophotometric detection. J. Agric. Food Chem. 2003, 51, 1513-1517.

(38)Method 4110-Determination of anions by ion chromatography. In Standard Methods for the Examination of Water and Wastewater, $20^{\text {th }}$ Edition; Clesceri, L. S.; Greenberg, A. E.; Eaton, A. D., Eds.; American Public Health Association: Washington, DC, 1999.

(39)Devonshire, R.; Weiss, J. J. Nature of the transient species in the photochemistry of negative ions in aqueous solution. J. Phys. Chem. 1968, 72, 3815-3820.

(40)Chawla, O. P.; Arthur, N. L.; Fessenden, R. W. An electron spin resonance study of the photolysis of aqueous sulfite solutions. J. Phys. Chem. 1973, 77, 772-776.

(41)Jeevarajan, A. S.; Fessenden, R. W. ESR studies of $\mathrm{e}_{\mathrm{aq}}{ }^{-}$in liquid solution using photolytic production. J. Phys. Chem. 1989, 93, 3511-3514.

(42)Hayon, E.; Treinin, A.; Wilf, J. Electronic spectra, photochemistry, and autoxidation mechanism of the sulfite-bisulfite-pyrosulfite systems: The $\mathrm{SO}_{2}{ }^{-}, \mathrm{SO}_{3}{ }^{-}, \mathrm{SO}_{4}{ }^{-}$, and $\mathrm{SO}_{5}{ }^{-}$radicals. J. Amer. Chem. Soc. 1972, 94, 47-57.

(43)Ermakov, A. N.; Poskrebyshev, G. A.; Purmal, A. P. Sulfite oxidation: The state-ofthe-art of the problem. Kinetics and Catalysis, 1997, 38, 295-308. 
(44)Zuo, Y.; Zhan, J.; Wu, T. Effects of monochromatic UV-visible light and sunlight on Fe (III)-catalyzed oxidation of dissolved sulfur dioxide. J. Atmos. Chem. 2005, $50,195-210$.

(45)Taube, H. Observations on atom-transfer reactions. ACS Symposium Series, 1982 , 198, 151-179. 


\section{APPENDIX A}

\section{POTASSIUM FERRIOXALATE ACTINOMETRY}

\section{A.1 FERROZINE METHOD FOR IRON ANALYSIS}

\section{A.1.1 Apparatus}

1) UV-visible spectrophotometer

2) Volumetric Flask, $50 \mathrm{~mL}, 100 \mathrm{~mL}$

3) Pipettes: $0.5 \mathrm{~mL}, 1.0 \mathrm{~mL}, 5.0 \mathrm{~mL}, 10 \mathrm{~mL}$

4) Amber glass bottles: $100 \mathrm{~mL}, 250 \mathrm{~mL}$

5) Centrifuge tube: $15 \mathrm{~mL}$

Note: All glassware should be acid washed with dilute nitric acid (2\%) and then rinsed with deionized water at least three times prior to use.

\section{A.1.2 Reagents}

1) Ferrous ammonium sulfate $\left(\mathrm{Fe}\left(\mathrm{NH}_{4}\right)_{2}(\mathrm{SO} 4)_{2} \cdot 6 \mathrm{H}_{2} \mathrm{O}\right.$, purity $\left.99.997 \%\right)$

2) Ferrozine (3-(2-pyridyl)-5,6-diphenyl-1,2,4-triazine-p,p'-disulfonic acid)

3) Ammonium acetate, $\mathrm{NH}_{4} \mathrm{C}_{2} \mathrm{H}_{3} \mathrm{O}_{2}$

4) Hydroxylamine hydrochloride, $\mathrm{NH}_{2} \mathrm{OH} \cdot \mathrm{HCl}$

5) $\mathrm{HCl}$, concentrated

6) $\mathrm{HNO}_{3}$, concentrated

7) $\mathrm{H}_{2} \mathrm{SO}_{4}$, concentrated

\section{A.1.3 Reagents preparation}


1) $1000 \mathrm{ppm}$ Ferrous Iron stock solution (commercial standard solution or make as follows)

Step1: Slowly add $2 \mathrm{~mL}$ of concentrated $\mathrm{H}_{2} \mathrm{SO}_{4}$ to $5 \mathrm{~mL}$ of DI water

Step2: Dissolve $0.7020 \mathrm{~g}$ of $\mathrm{Fe}\left(\mathrm{NH}_{4}\right)_{2}(\mathrm{SO} 4)_{2} \cdot 6 \mathrm{H}_{2} \mathrm{O}$

Step3: Dilute to $100 \mathrm{~mL}$ with DI water and mix well

Step4: Store the ferrous iron stock solution in an amber glass bottle

2) Ferrous Iron standard solution (Prepare daily for use)

a) $50 \mathrm{ppm}$ standard solution

Take $5 \mathrm{~mL}$ of stock solution and dilute to $100 \mathrm{~mL}$ with $1.2 \mathrm{~N} \mathrm{HCl}$ (using volumetric flask)

Or take $0.5 \mathrm{~mL}$ of stock solution and dilute to $10 \mathrm{~mL}$ with $1.2 \mathrm{~N} \mathrm{HCl}$ (using centrifuge tube)

b) $0.5,2.5,5,7.5$ and $10 \mathrm{ppm}$ standard solution

Take 1, 5, 10, 15 and $20 \mathrm{~mL}$ of $50 \mathrm{ppm}$ standard solution and dilute to $100 \mathrm{~mL}$ with 1.2 $\mathrm{N} \mathrm{HCl}$

Or take $0.1,0.5,1,1.5$ and $2 \mathrm{~mL}$ of $50 \mathrm{ppm}$ standard solution and dilute to $10 \mathrm{~mL}$ with $1.2 \mathrm{~N} \mathrm{HCl}$

3) $1.2 \mathrm{~N} \mathrm{HCl}$

$900 \mathrm{ml}$ of DI water $+100 \mathrm{ml}$ of Concentrated $\mathrm{HCl}$ into $1 \mathrm{~L}$ bottle

4) Ferrozine Solution

Step1: Place $0.15 \mathrm{~g}$ of Ferrozine in a $50 \mathrm{~mL}$ volumetric flask

Step2: Dissolve it with DI water containing 1 drop of concentrated $\mathrm{HCl}$ 
Step3: Dilute to $50 \mathrm{~mL}$

Step4: Store the Ferrozine solution in amber glass bottle

5) Acetate Buffer Solution

$10 \%$ ammonium acetate buffer solution (for iron analysis) obtained commercially

Or it can be prepared as described in page 451 of Standard Methods for the Examination

of Water and Wastewater, $20^{\text {th }}$ edition

6) Color Development Solution

Mix the Ferrozine solution and acetate buffer solution with 1:4 ratio and store in amber glass bottle.

7) Acid Quench Solution (0.7 $\left.\mathrm{M} \mathrm{HNO}_{3}\right)$

$955 \mathrm{~mL}$ of DI water $+45 \mathrm{~mL}$ of concentrated $\mathrm{HNO}_{3}$. Store in glass bottle.

8) Reductant Solution (10\% of hydroxylamine hydrochloride Solution)

Dilute $10 \mathrm{~g}$ of $\mathrm{NH}_{2} \mathrm{OH} \cdot \mathrm{HCl}$ in $100 \mathrm{~mL}$ of water. Store in an amber glass bottle.

\section{A.1.4 Procedures of ferrous iron and total iron analysis}

1) Calibration standard

Step1: Transfer $1 \mathrm{~mL}$ of each standard ferrous iron solution to a spectrophotometer cell Step2: Add $1 \mathrm{~mL}$ of Acid Quench solution

Step3: Add $1 \mathrm{~mL}$ of Color development solution

Step4: Mix well and allow 5 to 10 minutes for full color development

Step5: Measure the absorbance of iron-ferrozine complex and plot the standard curve

2) Samples for Ferrous Iron Analysis

Step1: Transfer $1 \mathrm{~mL}$ of sample to a spectrophotometer cell 
Step2: Add $1 \mathrm{~mL}$ of Acid Quench solution

Step3: Add $1 \mathrm{~mL}$ of Color development solution

Step4: Mix well and allow 5 to 10 minutes for full color development

Step5: Measure the absorbance of iron-ferrozine complex

Step6: Determine the concentration of ferrous iron in sample using standard curve

3) Samples for Total Iron Analysis

Step1: Transfer $1 \mathrm{~mL}$ of sample to a spectrophotometer cell

Step2: Add $1 \mathrm{~mL}$ of Reductant solution

Step3: Add $1 \mathrm{~mL}$ of Color development solution

Step4: Mix well and allow 5 to 10 minutes for full color development

Step5: Measure the absorbance of iron-ferrozine complex

Step6: Determine the concentration of ferrous iron in sample using standard curve

\section{A.2 POTASSIUM FERRIOXALATE AS CHEMICAL ACTINOMETER}

\section{A.2.1 Preparation of Actinometer Solution}

1) Prepare approximately $0.2 \mathrm{M} \mathrm{Fe} 2(\mathrm{SO} 4) 3$ solution.

2) Prepare a standard solution of (at least $100 \mathrm{ml}$ ) of $\mathrm{K}_{2} \mathrm{C}_{2} \mathrm{O}_{4}$ such that its molarity is six times that of the $\mathrm{Fe}_{2}\left(\mathrm{SO}_{4}\right)_{3}$ solution (approximately $1.2 \mathrm{M} \mathrm{K}_{2} \mathrm{C}_{2} \mathrm{O}_{4}$ ).

3) When actinometer solution is needed, pipette $5 \mathrm{ml}$ of the $\mathrm{Fe}_{2}\left(\mathrm{SO}_{4}\right)_{3}$ solution and $5 \mathrm{ml}$ of the $\mathrm{K}_{2} \mathrm{C}_{2} \mathrm{O}_{4}$ solution into a $100 \mathrm{ml}$ volume flask and dilute to the mark with water. $\mathrm{Be}$ careful not to mix the two stock solutions. The stock solutions will provide an indefinite supply of actinometer solution and the $100 \mathrm{ml}$ will supply many runs and be good for about a month. 


\section{A.2.2 Intensity Measurements}

1) Pipet into the reaction vessel a volume of $\mathrm{K}_{3} \mathrm{Fe}\left(\mathrm{C}_{2} \mathrm{O}_{4}\right)_{3}$ equal to that of the sample to be irradiated.

2) Irradiate for an appropriate period of time (must be determined experimentally but should give an absorption after work-up between $0.2-1.8$ )

3) Mix irradiated solution thoroughly and pipet an aliquot $(1 \mathrm{ml})$ of the actinometer into the spectrophotometer cell.

4) Add $1 \mathrm{ml}$ of acid quench solution.

5) Add $1 \mathrm{~mL}$ color development solution.

6) Mix well and give 5 to 10 minutes for full color development.

7) Prepare a blank follows 3)-5) with a non-irradiated volume of actinometer equal to the aliquot of irradiated sample withdrawn.

8) Measure the absorbance of the solutions 6) and 7) vs. water at $562 \mathrm{~nm}$ and take the difference. (Note: one can measure the absorption of 6) vs. 7) but the absorbance of the blank should be occasionally checked to test the quality of the actinometer solution. If a value greater than $\mathrm{A}=0.06$ is obtained for 7 , a new solution should be prepared.)

\section{A.2.3 Calculation of Light Intensity}

1) From the table below, select the appropriate quantum yield for ferrous production.

2) Using the absorption obtained, calculate the light intensity from the following formula:

$$
I(\text { Einstein } / \min )=\frac{A V_{2} V_{3}}{\varepsilon d \phi_{\lambda} t V_{1}}
$$

Where 
$\mathrm{A}=$ absorbance (at $562 \mathrm{~nm}$ ) of irradiated actinometer solution corrected for absorption of blank

$\mathrm{d}=$ path length $(\mathrm{cm})$ of absorption cell used in measurement of $\mathrm{A}$ $\varepsilon=$ extinction co-efficient of ferrous iron-ferrozine complex at $562 \mathrm{~nm}\left(\mathrm{~mL} \mathrm{~mol}^{-1} \mathrm{~cm}^{-1}\right)$, can be calibrated by ferrous iron absorbance standard curve

$\phi_{\lambda}=$ quantum yield of ferrous production at wavelength of light used

$\mathrm{V}_{1}=$ Volume (in $\mathrm{mL}$ ) of irradiated actinometer solution withdrawn

$\mathrm{V}_{2}=$ volume (in $\left.\mathrm{mL}\right)$ of actinometer irradiated

$\mathrm{V}_{3}=$ volume $($ in $\mathrm{mL})$ of solution in spectrophotometer cell $(3 \mathrm{~mL})$

$\mathrm{t}=$ irradiation time in minutes

\section{A.2.4 Corrections}

As light filtering is generally not perfect and $\mathrm{K}_{3} \mathrm{Fe}\left(\mathrm{C}_{2} \mathrm{O}_{4}\right)_{3}$ generally absorbs at wavelengths where irradiated solutions do not, one should determine the light intensity with a cell (containing the solvent used for the sample irradiation) in front of the actinometer and then with the cell containing the sample solution. A comparison gives a percentage to be used as a correction in calculating light intensities.

\section{Quantum Yields of Ferrous Production}

\begin{tabular}{|c|c|c|}
\hline$\lambda / \mathrm{nm}$ & $\phi_{\mathrm{Fe} 2+}$ & $\begin{array}{c}\phi_{\mathrm{Fe} 2+} \\
0.006 \mathrm{M} \text { Ferrioxalate }\end{array}$ \\
\hline 254 & 1.25 & - \\
\hline $297 / 302$ & 1.24 & - \\
\hline 313 & 1.24 & 1.16 \\
\hline 326 & 1.23 & - \\
\hline 334 & 1.23 & 1.14 \\
\hline 341 & 1.22 & Ferrioxalate \\
\hline
\end{tabular}




\begin{tabular}{|c|c|c|}
\hline$\lambda / \mathrm{nm}$ & $\begin{array}{c}\phi_{\mathrm{Fe} 2+} \\
0.006 \mathrm{M} \text { Ferrioxalate }\end{array}$ & $\begin{array}{c}\phi_{\mathrm{Fe} 2+} \\
0.15 \mathrm{M} \text { Ferrioxalate }\end{array}$ \\
\hline 352 & 1.21 & 1.14 \\
\hline 358 & 1.25 & - \\
\hline $361 / 366$ & 1.21 & - \\
\hline 364 & 1.28 & 1.18 \\
\hline $365 / 366$ & 1.21 & 1.15 \\
\hline 367 & 1.21 & 1.15 \\
\hline 382 & 1.18 & 1.12 \\
\hline 392 & 1.13 & 1.10 \\
\hline 402 & - & 1.07 \\
\hline 405 & 1.14 & - \\
\hline 407 & 1.19 & - \\
\hline 412 & - & 1.05 \\
\hline 416 & 1.12 & - \\
\hline 422 & - & 1.04 \\
\hline 433 & 1.11 & 1.01 \\
\hline 442 & - & 1.00 \\
\hline 451 & - & 0.96 \\
\hline 457 & - & 0.90 \\
\hline 458 & - & 0.845 \\
\hline 463 & - & 0.86 \\
\hline 468 & - & 0.91 \\
\hline 472 & - & 0.94 \\
\hline 480 & - & 0.93 \\
\hline 482 & - & 0.95 \\
\hline 493 & - & 0.94 \\
\hline 502 & - & 0.90 \\
\hline 509 & - & 0.86 \\
\hline 512 & - & 0.86 \\
\hline 522 & - & 0.65 \\
\hline 530 & - & 0.53 \\
\hline 546 & - & 0.15 \\
\hline $577 / 579$ & - & 0.013 \\
\hline
\end{tabular}


Reference (for Appendix A):

1. Murov, S. L.; Carmichael, I.; Hug, G. L. Handbook of photochemistry, $2^{\text {nd }}$ Edition, revised and expanded; Marcel Dekker Inc: New York, 1993.

2. Clesceri, L. S.; Greenberg, A. E.; Eaton, A. D. Standard methods for the examination of water and wastewater, $20^{\text {th }}$ Edition; American Public Health Association, Washington, DC, 1999, pp 450-455. 


\section{APPENDIX B}

\section{ADDITIONAL FIGURES}

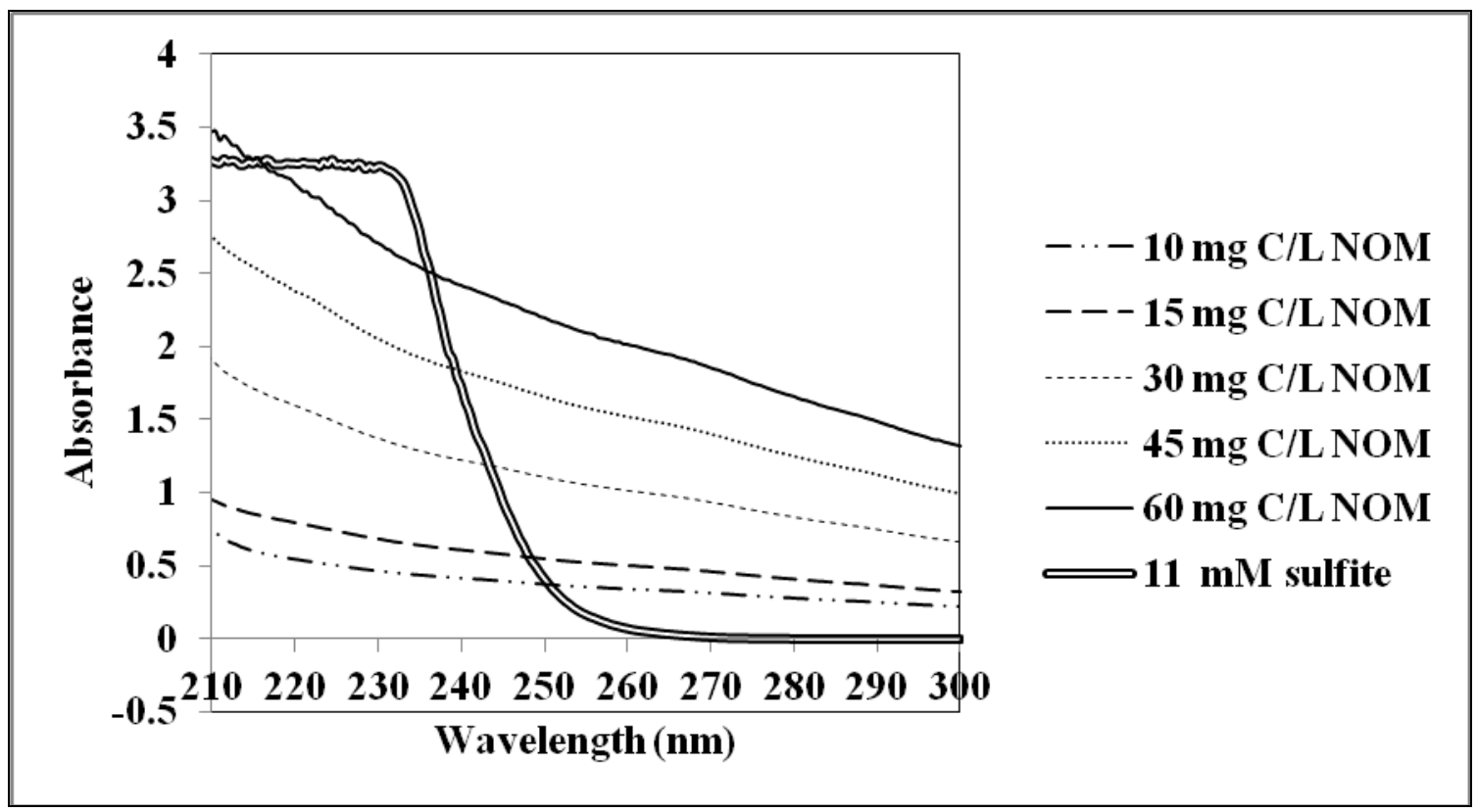

APPENDIX B.1 Absorbance of different levels of NOM and $11 \mathrm{mM}$ sulfite. 


\section{APPENDIX C}

\section{MATLAB CODE}

\section{C.1 Computer Program (MATLAB) to Predict Pseudo-First-Order Rate Constant of Perchlorate by UV/Sulfite ARP Using First-Order Decay Model}

$\%$ This coding is kinetic equation

function dcdt=deriv_ode(t,cmeas, $\mathrm{k})$

$\mathrm{dcdt}=-\mathrm{k} . * \mathrm{cmeas}$

$\mathrm{dcdt}=\mathrm{dcdt}^{\prime}$

$\%$ This coding is for solving kinetic equation

function cmod=calcmod_ode(beta,t,testdata)

$\operatorname{ct} 0=\operatorname{beta}(1)$;

$\mathrm{k}=\operatorname{beta}(2)$;

if $\mathrm{t}(1)==0$

$\operatorname{tspan}=\mathrm{t} ; \%$ if the vector $\mathrm{t}$ starts with $\mathrm{t}(1)=0$, then it can be used as tspan

else

tspan $=[0 ; \mathrm{t}] ; \%$ if $\mathrm{t}$ does not start with 0 , tspan must start with zero

end

[tout,cmod]=ode45(@deriv_ode, tspan, ct0,[], k);

$\%$ This script $m$-file inputs data and calls nlinfit_ode.m to conduct non-linear least squares regression

data $=$ load (data_name.txt');

$\%$ data_name.txt is the name of a text file that contains the data used in the regression.

$\%$ It is a matrix with the first column holding the values of the independent variable (e.g. time) 
$\%$ The subsequent columns hold values of the dependent variables (e.g. concentration)

$\%$ The data file must be in a directory accessible to MATLAB

$\mathrm{t}=\operatorname{data}(:, 1) ; \quad \%$ measured values of time

cmeas $=\operatorname{data}(:, 2) ; \quad \%$ measured values of concentration

beta $0=[11, .14] ; \quad \%$ initial guesses for values of parameters to be determined

[beta,resid,j]=nlinfit(t,cmeas,@calcmod_ode,beta0);

$\%$ call nlinfit.m to do least-squares regression

$\%$ calcmod.m is function that returns values of

$\%$ model concentrations given values of time and

$\%$ parameters beta. Uses format

$\% \mathrm{cmod}=$ calcmod(beta, $\mathrm{t})$, where cmod is vector of

$\%$ model values of independent variable (e.g.

$\%$ concentration)

betaci $=$ nlparci(beta,resid,j); \% call function to calculate confidence intervals

beta $\quad \%$ print to screen values of parameters

betaci $\%$ print to screen confidence intervals for parameters

\section{C.2 Computer Program (MATLAB) to Predict Quantum Yield for Sulfite Loss without NOM by UV/Sulfite ARP Using Developed Model in Section 4}

$\%$ This coding is kinetic equation

function $\mathrm{dcdt}=\mathrm{deriv} \_$ode $(\mathrm{t}, \mathrm{cmeas}, \mathrm{k}) \% \mathrm{k}$ represents quantum,

$\mathrm{L}=0.01 \%$ path length in meter

$\mathrm{e}=120.4 \%$ molar absorbtivity in $\mathrm{m}^{\wedge} 2 / \mathrm{mol}$

e_ $1=2.303 *$ e $\%$ base e molar absorbtivity

I_ $0=130 \%$ light intensity in unit $\mathrm{J} / \mathrm{m}^{\wedge} 2 / \mathrm{s}, 1 \mathrm{uW} / \mathrm{cm}^{\wedge} 2=0.01 \mathrm{~J} / \mathrm{m}^{\wedge} 2 / \mathrm{s}$

$\mathrm{W}=222 * 10^{\wedge}-9 \%$ wavelength of UV light in meter

$\mathrm{Na}=6.02 * 10^{\wedge} 23 \%$ avogadro's number in $\mathrm{mol}^{\wedge}-1$

$\mathrm{h}=6.626^{*} 10^{\wedge}-34 \%$ planck's number in J-s

c_l $=3 * 10^{\wedge} 8 \%$ speed of light in $\mathrm{m} / \mathrm{s}$ 
$\mathrm{I}=\mathrm{I} \_0^{*} \mathrm{~W} / \mathrm{Na} / \mathrm{h} / \mathrm{c} \_1 \%$ convert unit for light intensity to einstein $/ \mathrm{m}^{\wedge} 2 / \mathrm{s}$

$\mathrm{dcdt}=-\mathrm{k} . * \mathrm{I} *\left(1-\exp \left(-\mathrm{e} \_1 *\right.\right.$ cmeas $\left.\left.* \mathrm{~L}\right)\right) / \mathrm{L} * 3600$

$\%$ unit for quantum is $\mathrm{mol} / \mathrm{einstein}$

$\%$ rate of light absorption,

$\%$ cmeas $\left(\mathrm{mol} / \mathrm{m}^{\wedge} 3\right)$ here represent sulfite concentration at time $\mathrm{t}(\mathrm{h})$,

$\%$ make sure the unit is correct

$\%$ now the unit for $b$ is einstein $/ \mathrm{m}^{\wedge} 3 / \mathrm{h}$

$\mathrm{dcdt}=\mathrm{dcdt}^{\prime}$

$\%$ This coding is for solving kinetic equation

function cmod=calcmod_ode(beta,t,testdata)

ct0 $=$ beta $(1)$;

$\mathrm{k}=\operatorname{beta}(2)$;

if $\mathrm{t}(1)==0$

tspan $=\mathrm{t} ; \%$ if the vector $\mathrm{t}$ starts with $\mathrm{t}(1)=0$, then it can be used as tspan

else

tspan $=[0 ; t] ; \%$ if $t$ does not start with 0 , tspan must start with zero

end

[tout,cmod]=ode45(@deriv_ode, tspan, ct0,[], k);

$\%$ This script m-file inputs data and calls nlinfit_ode.m to conduct non-linear least squares regression

data $=$ load (data_name.txt');

$\%$ data_name.txt is the name of a text file that contains the data used in the regression.

$\%$ It is a matrix with the first column holding the values of the independent variable (e.g. time)

$\%$ The subsequent columns hold values of the dependent variables (e.g. concentration)

$\%$ The data file must be in a directory accessible to MATLAB 
$\mathrm{t}=\operatorname{data}(:, 1) ; \quad \%$ measured values of time

cmeas $=\operatorname{data}(:, 2) ; \quad \%$ measured values of concentration

beta $0=[10, .14] ; \quad \%$ initial guesses for values of parameters to be determined

[beta,resid,j]=nlinfit(t,cmeas,@calcmod_ode,beta0);

$\%$ call nlinfit.m to do least-squares regression

$\%$ calcmod.m is function that returns values of

$\%$ model concentrations given values of time and

$\%$ parameters beta. Uses format

$\% \mathrm{cmod}=$ calcmod(beta, $\mathrm{t})$, where $\mathrm{cmod}$ is vector of

$\%$ model values of independent variable (e.g.

$\%$ concentration)

betaci=nlparci(beta,resid,j); \% call function to calculate confidence intervals

beta $\quad \%$ print to screen values of parameters

betaci $\%$ print to screen confidence intervals for parameters

\section{C.3 Computer Program (MATLAB) to Predict Quantum Yield for Sulfite Loss}

with NOM by UV/Sulfite ARP Using Developed Model in Section 4

$\%$ This coding is kinetic equation

function dcdt=deriv_ode(t,c_meas,k) $\% \mathrm{k}$ represents quantum,

c_meas $=[]$

$\%$ input measured concentration here, sulfite first and followed by NOM

c_meas $=$ reshape(c_meas, 7,2) \% convert vector to matrix

sul $=$ c_meas $(1) \%$ measured concentration of sulfite

nom $=$ c_meas $(2) \%$ measured concentration of NOM

$\mathrm{L}=0.01 \%$ path length in meter

$\mathrm{e}=120.4 \%$ molar absorbtivity of sulfite in $\mathrm{m}^{\wedge} 2 / \mathrm{mol}$

e_su $1=2.303 *$ e $\%$ base e molar absorbtivity of sulfite

e_nom $=2.303 * 62.04 \%$ base e molar absorbtivity of NOM 
$\mathrm{a}=\mathrm{e} \_$su $1 *$ sul+e_nom*nom

$\%$ absorption coefficient for all dissolved compounds

$\%$ remember to convert unit of cnom to $\mathrm{mol} / \mathrm{m}^{\wedge} 3$

I_ $0=130 \%$ light intensity in unit $\mathrm{J} / \mathrm{m}^{\wedge} 2 / \mathrm{s}, 1 \mathrm{uW} / \mathrm{cm}^{\wedge} 2=0.01 \mathrm{~J} / \mathrm{m}^{\wedge} 2 / \mathrm{s}$

$\mathrm{W}=222 * 10^{\wedge}-9 \%$ wavelength in meter

$\mathrm{Na}=6.02 * 10^{\wedge} 23 \%$ avogadro's number in $\mathrm{mol}^{\wedge}-1$

$\mathrm{h}=6.626^{*} 10^{\wedge}-34 \%$ planck's number in J-s

c_lig $=3 * 10^{\wedge} 8 \%$ speed of light in $\mathrm{m} / \mathrm{s}$

$\mathrm{I}=\mathrm{I} \_{ }^{*} \mathrm{w} / \mathrm{Na} / \mathrm{h} / \mathrm{c} \_$lig $\%$ convert unit for light intensity to einstein $/ \mathrm{m}^{\wedge} 2 / \mathrm{s}$

$\operatorname{dcdt}(1)=-\mathrm{k}(1) * \mathrm{e} \_s u 1 * \operatorname{sul} \mathrm{I}^{*}(1-\exp (-\mathrm{a} * \mathrm{~L})) / \mathrm{L} / \mathrm{a} * 3600$

$\%$ unit for quantum is mol/einstein

$\%$ rate of light absorption,

$\%$ make sure the unit is correct

$\operatorname{dcdt}(2)=-\mathrm{k}(2) *$ e_nom*nom*I*(1-exp $(-\mathrm{a} * \mathrm{~L})) / \mathrm{L} / \mathrm{a} * 3600$

$\mathrm{dcdt}=\mathrm{dcdt}^{\prime}$

$\%$ This coding is for solving kinetic equation

function cmod=calcmod_ode(beta,t,testdata)

sul_0 $=\operatorname{beta}(1)$;

nom_0 $=\operatorname{beta}(2)$;

$\mathrm{k}(1)=\operatorname{beta}(3)$;

$\mathrm{k}(2)=\operatorname{beta}(4)$;

$\mathrm{t}=[$ ] $\%$ input measured time here

[tout,cmod]=ode45(@deriv_ode, t, [sul_0,nom_0],[],k);

cmod=reshape $(\operatorname{cmod}, 7 * 2,1) \%$ covert matrix to vector

$\%$ This script m-file inputs data and calls nlinfit_ode.m to conduct non-linear least squares regression 
data $=$ load (data_name.txt');

$\%$ data_name.txt is the name of a text file that contains the data used in the regression.

$\%$ It is a matrix with the first column holding the values of the independent variable (e.g. time)

$\%$ The subsequent columns hold values of the dependent variables (e.g. concentration)

$\%$ The data file must be in a directory accessible to MATLAB

$\mathrm{t}=\operatorname{data}(:, 1) ; \quad \%$ measured values of time

cmeas $=\operatorname{data}(:, 2) ; \quad \%$ measured values of concentration

beta $0=[11,4.15, .014, .014]$;

$\%$ initial guesses for values of parameters to be determined

[beta,resid,j]=nlinfit(t,cmeas,@calcmod_ode,beta0);

$\%$ call nlinfit.m to do least-squares regression

$\%$ calcmod.m is function that returns values of

$\%$ model concentrations given values of time and

$\%$ parameters beta. Uses format

$\% \mathrm{cmod}=$ calcmod(beta, $\mathrm{t})$, where cmod is vector of

$\%$ model values of independent variable (e.g.

$\%$ concentration)

betaci $=$ nlparci(beta,resid,j); $\%$ call function to calculate confidence intervals

beta $\quad \%$ print to screen values of parameters

betaci $\%$ print to screen confidence intervals for parameters 


\section{VITA}

Yuhang Duan received her Bachelor of Science degree in agricultural resources and environmental science from the Agricultural University of Hebei, China, in June 2006. She entered the Department of Civil Engineering at Texas A\&M University in September 2010 and received her Master of Science degree in August 2012. Her research interests include advanced reduction processes and removal of mercury from wastewater.

Ms. Duan may be reached: Environmental Engineering and Water Resource Division (WERC 205-C), Department of Civil Engineering, Texas A\&M University, College Station, TX 77843-3136. Her email is dyh1988@neo.tamu.edu. 